\title{
Por Que os Estados Brasileiros Têm Reações Assimétricas a Choques na Política Monetária?
}

\author{
Roberta de Moraes Rocha*, Marcelo Eduardo Alves da Silva ${ }^{\dagger}$, Sónia \\ Maria Fonseca Pereira Oliveira Gomes ${ }^{\ddagger}$
}

Conteúdo: 1. Introdução; 2. Modelo Empírico; 3. Dados; 4. Especificação, Estimação e Identificação dos Modelos SVARs; 5. Funções de Impulso-Resposta Estaduais;

6. Porque as Economias Tendem a Reagir Diferentemente a Choques Monetários;

7. Considerações Finais; A. Apêndice.

A primeira parte deste artigo examina se a política monetária apresenta impactos diferenciados sobre diferentes estados brasileiros. Uma análise das funções de resposta a impulso, extraídas de modelos vetoriais auto-regressivos estruturais (SVAR) estimados para diversos estados brasileiros, aponta para assimetrias nas respostas dos produtos estaduais a choques monetários. A segunda parte investiga quais características estaduais poderiam explicar tais assimetrias com base em um modelo de regressão. A evidência sugere que a intensidade da resposta do produto estadual é relacionada diretamente as variáveis de composição industrial, grau de abertura e ao volume de crédito, as quais dão suporte aos canais de transmissão da taxa de juros e de crédito da política monetária. Os resultados ainda oferecem algum suporte às teorias do canal demográfico e do mercado de trabalho (socioeconômico). Diante dessas evidências, recomenda-se cautela na condução da política monetária no Brasil, uma vez que a implementação de políticas que ignorem a diversidade econômica e social do país podem ter efeitos não desejáveis, podendo aprofundar ainda mais as disparidades regionais do país.

This paper examines whether monetary policy has similar effects across Brazilian States. Our impulse response functions from state-level estimated structural vector autoregression (SVAR) reveal asymmetries in output responses to a monetary policy shock. We further investigate the reasons

*Doutora em Economia - PIMES / UFPE E-mail: roberta_rocha_pe@yahoo.com.br

${ }^{\dagger} \mathrm{PhD}$ em Economia - University of North Carolina at Chapel Hill E-mail: marcelo.easilva@ufpe.br

${ }^{\ddagger}$ Doutora em Economia - PIMES / UFPE E-mail: sonia.mf pereira@ufpe.br 
for the measured cross-state differential policy responses. The evidence suggests that the size of a state's response is related to economy's industry-mix variables, to the openness degree and to the state's credit volume providing evidence of an interest rate and credit-channels for monetary policy. The results also present some support to for demographic and labor markets channels theories. The results offer some words of caution for the monetary policy management in Brazil. Policy actions that fail to acknowledge the state-level socio-economic diversity may yield undesirable results and may increase regional disparities within the country.

Palavras-chave: Choques Monetários; Canais de Transmissão; Vetor Auto-Regressivo Estrutural (SVAR).

Códigos JEL: $\quad$ E52; C32; E32.

\section{INTRODUÇÃO}

A preocupação sobre os impactos diferenciados de choques monetários sobre a dinâmica econômica das regiões de um mesmo país ou de países que compõe uma união monetária (e.g., Euro) tem se tornando objeto de interesse recente na literatura econômica. Entre outros fatores, dois principais canais de transmissão da política monetária sobre o produto são analisados para explicar porque as economias regionais tendem a ter reações assimétricas a choques nos agregados monetários, são eles o canal da taxa de juros e o canal de crédito. A base de explicação do primeiro canal está nas diferenças entre as estruturas produtivas regionais, sugerindo que regiões com setores mais sensíveis à taxa de juros acabam respondendo mais intensamente a choques monetários. Por outro lado, o canal de crédito baseia-se nas disparidades entre o nível de desenvolvimento financeiro regional, com regiões de menor desenvolvimento financeiro sendo mais impactadas por choques monetários.

Carlino e Defina (1998) evidenciam que choques na política monetária têm efeitos assimétricos sobre o produto dos diferentes estados Norte-Americanos, e propõe algumas explicações baseadas nos canais de transmissão de crédito e da taxa de juros. Eles mostram que a magnitude da resposta dos produtos estaduais a choques na política monetária é positivamente correlacionada com a participação da indústria de manufaturas no produto estadual, o que é coerente com o canal da taxa de juros. Por outro lado, os seus resultados não foram condizentes com o canal de crédito. Gerlach e Smets (1995) observam que os efeitos da política monetária sobre o produto dos países G-7 tendem a ser bem próximos, não evidenciando, portanto, significativas disparidades nas reações destas economias a choques monetários. Considerando os países da União Monetária Européia, Carlino e Defina (2000) mostram que - com base em características da estrutura produtiva que são consistentes com o canal da taxa de juros - alguns desses países tendem a ter reações parecidas a choques monetários, e eles agrupam os países em três grupos de acordo com a intensidade do impacto. De acordo com os autores, Irlanda, Finlândia e Espanha seriam os países potencialmente mais sensíveis a choques monetários, enquanto França, Itália, e os Países Baixos fazem parte do grupo de países que são menos sensíveis. Por fim, Áustria, Bulgária, Portugal, Alemanha e Luxemburgo pertenceriam ao grupo de países com reações a choques monetários que não se distanciam da média.

Francis et alii (2009) estendem a análise às regiões metropolitanas dos Estados Unidos. Eles observam que há importantes assimetrias nas reações das economias das regiões metropolitanas a choques monetários. Além dos tradicionais canais da taxa de juros e crédito, eles sugerem três outros canais demográfico e socioeconômico, do mercado de habitação, e da estrutura fiscal -, para explicar porque os municípios reagem diferentemente a choques monetários. De acordo com os resultados desses autores, as características demográficas e do governo local são fatores potenciais de explicação para os resultados estimados. 
Salvo algumas exceções, a análise da repercussão de choques monetários sobre o dinamismo das economias estaduais ainda é pouco explorada no Brasil. Araújo Jr. (2004), com o objetivo de comparar as respostas dos produtos da Região Sul com a Região Nordeste a choques monetários, estima um modelo VAR, e com base na função de impulso-resposta obtém indicações de que a Região Sul é mais fortemente influenciada pela política monetária. Bertanha e Haddad (2008) estimam um modelo VAR, controlando pela dependência espacial entre os estados, para analisar a repercussão da política monetária sobre diferentes unidades geográficas do país. Eles utilizam a variável "emprego" como proxy do nível da atividade produtiva. Os resultados dos autores indicam que o nível de emprego dos estados localizados nas Regiões Norte e Nordeste é mais vulnerável a choques na política monetária, e esse impacto é mais significativo quando não é considerada a inter-relação de dependência espacial entre as unidades da federação.

Observa-se que para o Brasil há evidências empíricas que corroboram com a hipótese de que os estados brasileiros tendem a reagir de forma diferenciada a choques monetários. Porém, poucos são os estudos que investigam os porquês dessas reações diferenciadas. Na verdade, identifica-se na literatura apenas um único esforço de pesquisa realizado por Vasconcelos e Fonseca (2002). Os autores, baseandose em Carlino e Defina (1998), fazem um exame exploratório das possíveis assimetrias que o produto das regiões e dos estados do Brasil pode apresentar em resposta a choques monetários, observando dados da composição industrial, da estrutura das empresas (porte) e da importância financeira dos estados e das grandes regiões. De posse desses indicadores, Vasconcelos e Fonseca (2002) conjecturam sobre possíveis razões que fariam com que as unidades geográficas brasileiras respondessem assimetricamente a choques monetários. Contudo, eles não testam empiricamente as suas suposições.

Buscando contribuir para um melhor entendimento da repercussão da política monetária sobre os diferentes estados brasileiros, este artigo tem dois objetivos. Primeiro, investiga-se se choques na política monetária apresentam impactos diferenciados sobre os diferentes estados brasileiros. Esta análise é realizada a partir da função de impulso-resposta, que relaciona o índice de produção industrial a inovações no instrumento de política monetária. Para isso, estima-se um modelo vetorial auto-regressivo estrutural para cada um dos estados. ${ }^{1}$ O segundo objetivo - principal contribuição do artigo - inova ao testar empiricamente, com base em um modelo de regressão, as razões pelas quais as respostas dos estados brasileiros a choques monetários são diferenciadas.

Este estudo torna-se ainda mais interessante para o Brasil, país caracterizado por ter uma estrutura produtiva regional muito diversificada e com diferentes níveis de desenvolvimento financeiro, além das significativas disparidades de renda regional que nele impera, as quais podem ser potencializadas em períodos de contração monetária.

Os resultados mostram que os estados tendem a ter reações assimétricas a choques na política monetária. Porém, não foi encontrado um padrão que pudesse comparar a intensidade de respostas entre as grandes regiões, assim como realizado por Araújo Jr. (2004) e Bertanha e Haddad (2008). Os resultados apontaram que o Estado do Amazonas, Rio Grande do Sul e Goiás são os mais sensíveis a choques monetários, enquanto os estados do Paraná, Pernambuco e Bahia são os menos sensíveis. A segunda parte da análise sugere que aqueles estados com uma maior indústria extrativista reagem menos intensamente à política monetária, e os que têm um maior volume de depósitos bancários, respondem mais intensamente. Além destes, têm-se indicações de que os estados com uma maior densidade demográfica, e com um maior grau de abertura comercial devem apresentar menores reações à política monetária. Os nossos resultados, portanto, oferecem suporte a importância dos canais de crédito e o sócio-demográfico, como potenciais explicações para as respostas assimétricas dos estados brasileiros a choques na política monetária.

\footnotetext{
${ }^{1}$ Este primeiro objetivo não é novo uma vez que trabalhos semelhantes já foram realizados para o Brasil (e.g., Araújo Jr., 2004, Bertanha e Haddad, 2008). A novidade consiste na aplicação da metodologia a todos os estados brasileiros onde há informações disponíveis sobre produção industrial.
} 
Além desta Introdução, a Seção 2 descreve o modelo empírico, a Seção 3 os dados, a Seção 4 apresenta os resultados das estimações dos VARs, a quinta seção destina-se a investigação da assimetria de respostas a choques monetários e a sexta seção relata as Considerações Finais.

\section{MODELO EMPÍRICO}

A relação dinâmica entre as variáveis de interesse pode ser representada através de um modelo Vetorial Auto-Regressivo Estrutural (SVAR) da seguinte maneira:

$$
y_{t}^{\prime} A_{0}=\sum_{l=1}^{p} y_{t-l}^{\prime} A_{l}+\epsilon_{t}^{\prime} \text { para } 1 \leq t \leq T
$$

onde:

$y_{t}$ é um vetor coluna $n \times 1$ das variáveis endógenas do modelo;

$A_{0}$ é uma matriz $n \times n$ dos coeficientes contemporâneos;

$A_{l}$ é uma matriz $n \times n$ dos parâmetros das variáveis defasadas para $1 \leq l \leq p$;

$\epsilon_{t}$ é um vetor coluna $n \times 1$ dos distúrbios estruturais;

$p$ é a ordem de defasagem;

$T$ é o tamanho da amostra.

A distribuição de $\epsilon_{t}$, condicional as informações passadas, é Gaussiana com média e matriz de variância-covariância dada por $E\left(\epsilon_{t} \mid y_{t}, \ldots, y_{t-1}\right)=0$ e $E\left(\epsilon_{t} \epsilon_{t-1}^{\prime} \mid y_{1}, \ldots, y_{t-1}\right)=I_{n \times n}$, respectivamente. Pós-multiplicando todos os elementos de (1) por $A_{0}^{-1}$, nós obtemos o Modelo Vetorial AutoRegressivo em sua forma reduzida:

$$
y_{t}^{\prime}=\sum_{l=1}^{p} y_{t-l^{\prime}} B_{l}+u_{t}^{\prime} \text { para } 1 \leq t \leq T
$$

onde $B_{l}=A_{l} A_{0}^{-1}$ (para $l=1,2, \ldots, p$ ), $u_{t}^{\prime}=\epsilon_{t}^{\prime} A_{0}^{-1}$ e $E\left[u_{t}^{\prime} u_{t}\right]=\Omega=\left(A_{0}^{\prime} A_{0}\right)_{-1}$ é a matriz de variância-covariância dos resíduos na forma reduzida.

O modelo VAR na sua forma reduzida é estimado para cada um dos estados considerados neste trabalho utilizando dados mensais. O vetor $y_{t}$ é composto por uma medida da taxa de crescimento do produto agregado nacional, $\Delta P I B_{t}^{B R}$; por uma medida da taxa de crescimento do produto estadual, $\triangle P I B_{t}^{j}$, onde o sobrescrito $j$ representa a economia estadual $j$; por uma medida de variação do nível de preços ao consumidor, $\Delta P_{t}^{B R}$; e pela variável que representa o instrumento da política monetária, a taxa de juros, $r_{t}$.

$$
y_{t}=\left(\Delta P I B_{t}^{B R}, \Delta P I B_{t}^{j}, \Delta P_{t}^{B R}, r_{t}\right)^{\prime}
$$

Muito embora, o modelo a ser estimado consista no VAR na sua forma reduzida (2), as questões de interesse deste artigo demandam a obtenção de funções de resposta a impulso ortogonais, as quais representam as respostas endógenas das variáveis do sistema a um impulso em um dos elementos do vetor $\epsilon_{t}$. Nós adotamos uma estratégia de identificação recursiva (decomposição de Cholesky) para identificar cada elemento deste vetor.

A identificação recursiva significa, por exemplo, que a primeira variável na ordenação não é afetada contemporaneamente pelas demais variáveis do sistema, enquanto que a segunda variável é afetada contemporaneamente pela primeira, mas não é afetada pelas demais. A terceira variável, por sua vez, é afetada contemporaneamente pela primeira e segunda variável, mas não é afetada pela quarta. Por fim, a última variável na ordenação é afetada contemporaneamente pelas três primeiras, mas não afeta 
nenhuma delas contemporaneamente. Este é o procedimento utilizado, por exemplo, por Sims (1980), Bernanke (1986), Carlino e Defina (1999), Minella (2003), Owyang e Wall (2009), dentre outros.

A ordenação adotada neste artigo é a seguinte: taxa de crescimento do produto nacional, taxa de crescimento do produto estadual, inflação e taxa de juros. Esta ordem de entrada das variáveis é justificada pelo fato das decisões de produção serem tomadas com certa defasagem, enquanto que os preços tendem a responder mais rapidamente. Além disto, é assumido que as decisões de política monetária são tomadas com base em informações sobre os comportamentos recentes dos produtos e da inflação. ${ }^{2}$

\section{DADOS}

Os dados mensais cobrem o período de janeiro de 1995 a novembro de 2010 para todos os estados, à exceção dos estados do Amazonas, Goiás e Pará, para os quais os dados do índice de produção industrial apenas tornaram-se disponível a partir do ano de 2002. A unidade geográfica de referência para a análise são todos os estados que se têm dados disponíveis dos índices de produção industrial: Amazonas, Pará, Ceará, Pernambuco, Bahia, Minas Gerais, Espírito Santos, Rio de Janeiro, São Paulo, Paraná, Santa Catarina, Rio Grande do Sul, e Goiás.

Para a estimação do modelo VAR, consideraram-se quatro variáveis: um indicador do nível de atividade econômica agregada para o Brasil, neste caso foi utilizado o índice de produção industrial (série encadeada) para o Brasil obtido no IBGE; um indicador do nível de produção dos estados, o Índice de Produção Industrial estadual (série encadeada), fornecido pela Pesquisa Industrial Mensal do IBGE; um indicador sobre o comportamento dos preços na economia agregada, o qual é representado pela taxa de inflação calculada como a taxa de variação dos preços baseado no IPCA; e, por fim, um indicador do instrumento de política monetária, neste caso é utilizado a taxa de juros Selic-Over fornecida pelo Banco Central do Brasil.

As séries de produção industrial são ajustadas para a presença da sazonalidade. As taxas de crescimento do produto agregado e estaduais foram calculadas como a primeira diferença do logaritmo natural dos respectivos índices de produção industrial, enquanto que a variável inflação foi calculada como a primeira diferença do logaritmo natural do índice de preços calculado com base no IPCA. A taxa de juros é definida como a taxa Selic-over mensal.

\section{ESPECIFICAÇÃO, ESTIMAÇÃO E IDENTIFICAÇÃO DOS MODELOS SVARS}

\subsection{Resultados dos testes de especificação}

O primeiro passo na metodologia adotada neste artigo consiste em testar a hipótese de estacionariedade das séries. Foram implementados dois testes. O primeiro consiste no teste de Dickey-Fuller Aumentado (ADF) e o segundo no teste de estacionariedade de Kwiatkowski-Phillips-Schmidt-Shin (KPSS). A Tabela 1 abaixo apresenta os resultados para o teste ADF, enquanto que a Tabela A-1 no Apêndice apresenta os resultados do teste KPSS. Em geral, ambos os testes apontam para a estacionariedade das séries a $5 \%$ de significância. Uma vez verificado que as séries são estacionárias, o segundo passo consiste na determinação da ordem de defasagem de cada VAR. Isto é feito através da minimização de uma função de perda. De acordo com a recomendação de Ivanov e Kilian (2005) para VARs com dados mensais, nós adotamos o Critério de Informação de Akaike (AIC) na seleção das defasagens dos modelos

\footnotetext{
${ }^{2}$ O uso de dados mensais oferece suporte adicional a esta identificação. Carlino e Defina (1998, 1999), Minella (2003) adotam ordenação semelhante.
} 


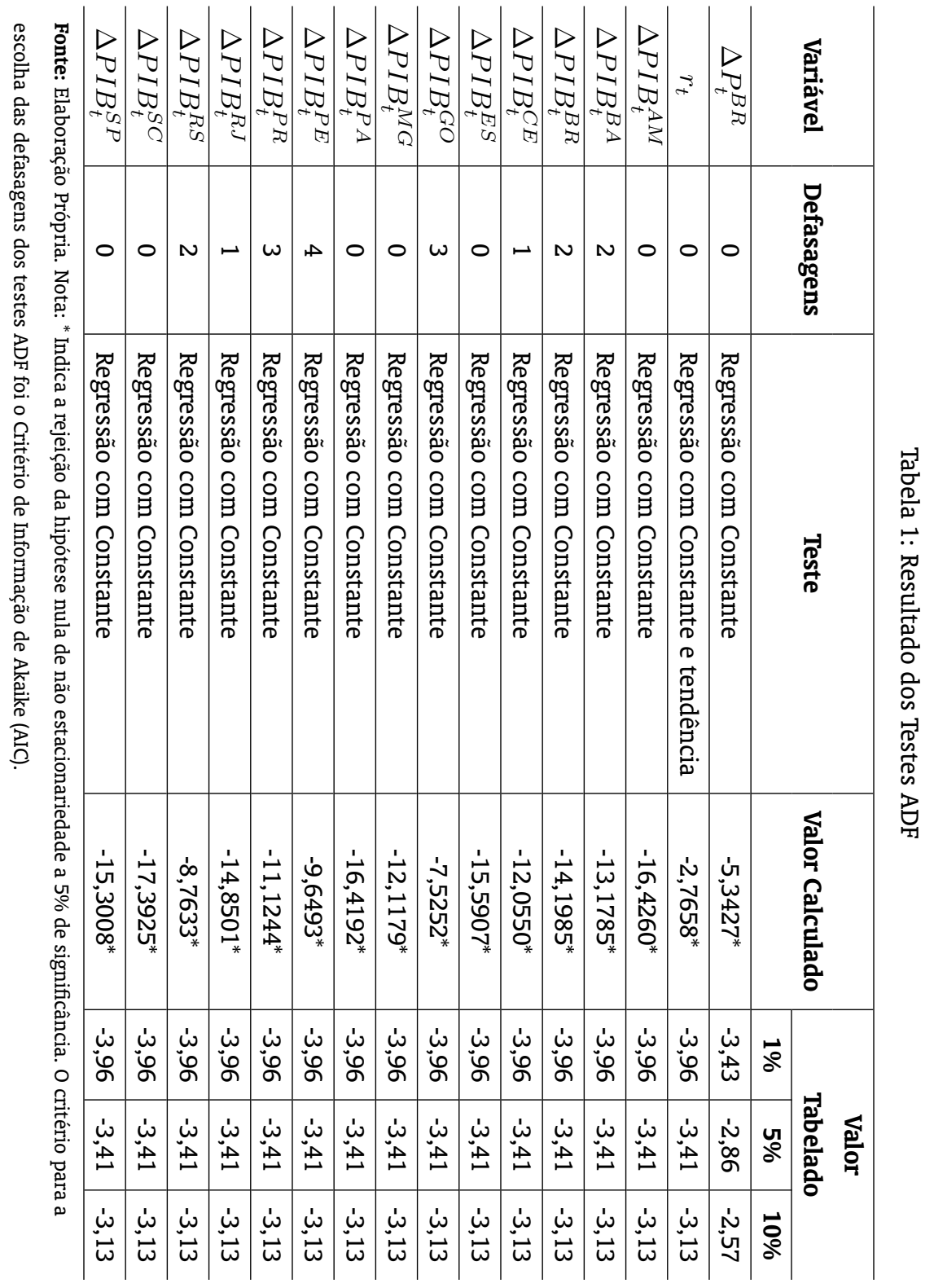


VARs. ${ }^{3}$ A Tabela 2 apresenta os resultados da seleção das defasagens, incluindo o número de defasagens utilizado na estimação dos modelos para cada um dos estados em sua forma reduzida (equação 2).

Tabela 2: Seleção de defasagens no VAR

\begin{tabular}{|c|c|c|c|c|c|}
\hline \multirow[b]{2}{*}{ Modelos } & \multirow{2}{*}{$\begin{array}{c}\text { Tipo de } \\
\text { modelo } \\
\text { estimado }\end{array}$} & \multicolumn{4}{|c|}{ Critérios de Informação } \\
\hline & & $\begin{array}{c}\text { Akaike Info } \\
\text { Criterion }\end{array}$ & $\begin{array}{c}\text { Final } \\
\text { Prediction Error }\end{array}$ & $\begin{array}{c}\text { Hannan-Quinn } \\
\text { Criterion }\end{array}$ & $\begin{array}{l}\text { Schwarz } \\
\text { Criterion }\end{array}$ \\
\hline$\Delta P I B_{t}^{B R} \Delta P I B_{t}^{A M} \Delta P_{t}^{B R} r_{t}$ & 3 & 9 & 2 & 1 & 1 \\
\hline$\Delta P I B_{t}^{B R} \Delta P I B_{t}^{B A} \Delta P_{t}^{B R} r_{t}$ & 2 & 2 & 2 & 1 & 1 \\
\hline$\Delta P I B_{t}^{B R} \Delta P I B_{t}^{C E} \Delta P_{t}^{B R} r_{t}$ & 2 & 2 & 2 & 1 & 1 \\
\hline$\Delta P I B_{t}^{B R} \Delta P I B_{t}^{E S} \Delta P_{t}^{B R} r_{t}$ & 1 & 1 & 1 & 1 & 1 \\
\hline$\Delta P I B_{t}^{B R} \Delta P I B_{t}^{G O} \Delta P_{t}^{B R} r_{t}$ & 2 & 2 & 2 & 1 & 1 \\
\hline$\Delta P I B_{t}^{B R} \Delta P I B_{t}^{M G} \Delta P_{t}^{B R} r_{t}$ & 2 & 1 & 1 & 1 & 1 \\
\hline$\Delta P I B_{t}^{B R} \Delta P I B_{t}^{P A} \Delta P_{t}^{B R} r_{t}$ & 2 & 2 & 2 & 1 & 1 \\
\hline$\Delta P I B_{t}^{B R} \Delta P I B_{t}^{P E} \Delta P_{t}^{B R} r_{t}$ & 2 & 2 & 2 & 1 & 1 \\
\hline$\Delta P I B_{t}^{B R} \Delta P I B_{t}^{P R} \Delta P_{t}^{B R} r_{t}$ & 1 & 1 & 1 & 1 & 1 \\
\hline$\Delta P I B_{t}^{B R} \Delta P I B_{t}^{R J} \Delta P_{t}^{B R} r_{t}$ & 2 & 2 & 2 & 1 & 1 \\
\hline$\Delta P I B_{t}^{B R} \Delta P I B_{t}^{R S} \Delta P_{t}^{B R} r_{t}$ & 1 & 1 & 1 & 1 & 1 \\
\hline$\Delta P I B_{t}^{B R} \Delta P I B_{t}^{S C} \Delta P_{t}^{B R} r_{t}$ & 1 & 1 & 1 & 1 & 1 \\
\hline$\Delta P I B_{t}^{B R} \Delta P I B_{t}^{S P} \Delta P_{t}^{B R} r_{t}$ & 2 & 2 & 2 & 1 & 1 \\
\hline
\end{tabular}

Fonte: Elaboração Própria.

Os modelos em sua forma reduzida são estimados por Mínimos Quadrados Ordinários (MQO). Uma vez estimados os modelos para cada um dos estados, os resíduos de cada modelo foram testados para a presença de autocorrelação e para a presença de heterocedasticidade condicional. Quando se detectou a presença de resíduos autocorrelacionados, foi feita uma tentativa de se obter resíduos melhores através da introdução de uma ou duas defasagens. Adicionalmente, nós testamos para a normalidade dos resíduos. As Tabelas A-2, A-3 e A-4 no Apêndice A apresentam os resultados desta análise. De um modo geral, os resultados são pobres em termos de normalidade, mas são relativamente satisfatórios em termos de autocorrelação e de heterocedasticidade condicional.

O objetivo da estimação é recuperar os parâmetros da forma estrutural e com isto obter as funções de resposta a impulso ortogonais dos produtos estaduais para cada um dos estados em resposta a um choque de $1 \%$ na taxa de juros. Nós utilizamos o procedimento de dois estágios sugerido por Bernanke (1986) e comum na literatura (ver Carlino e Defina, 1998, 1999) para obter as funções de resposta a impulso ortogonais. O primeiro estágio consiste em estimar cada um dos modelos em suas formas reduzidas, como discutido acima. A partir dos parâmetros estimados, e da imposição de restrições no modelo estrutural, é possível então recuperar os parâmetros do modelo estrutural. Portanto, o primeiro passo consiste na estimação do modelo na forma reduzida (2), utilizando o método de mínimos quadrados ordinários, e na obtenção dos resíduos na forma reduzida $u_{t}=A_{0}^{-1} \epsilon_{t}$. A partir disto, o segundo estágio envolve a imposição de restrições que permitam a identificação dos erros do modelo estrutural.

Dados os resíduos da forma reduzida, $u_{t}$, é possível recuperar os erros da forma estrutural, $\epsilon_{t}$, a partir da imposição de, no mínimo, $n(n+1) / 2$ restrições ao sistema. A estratégia de identificação adotada neste artigo (decomposição de Cholesky) assume que a matriz de coeficientes contemporâneos, $A_{0}$, é triangular inferior com 1's na diagonal principal, garantindo as condições necessárias para a identificação dos choques estruturais. Em conjunto estas restrições podem ser representadas como:

\footnotetext{
${ }^{3}$ A exceção a este procedimento consistiu no VAR estimado para o Estado do Amazonas. O AIC apontou para um número de defasagens elevado, o que diante do número reduzido de observações para este estado em particular, poderia comprometer nossas estimações. Neste caso, nós optamos por um VAR com um número menor de defasagens.
} 


$$
\left[\begin{array}{l}
u_{t}^{1} \\
u_{t}^{2} \\
u_{t}^{3} \\
u_{t}^{4}
\end{array}\right]=\left[\begin{array}{cccc}
1 & 0 & 0 & 0 \\
a_{21} & 1 & 0 & 0 \\
a_{31} & a_{32} & 1 & 0 \\
a_{41} & a_{42} & a_{32} & 1
\end{array}\right]^{-1}\left[\begin{array}{l}
e_{t}^{1} \\
e_{t}^{2} \\
e_{t}^{3} \\
e_{t}^{4}
\end{array}\right]
$$

onde $u_{t}^{i}$ representa os resíduos da equação $i$ da forma reduzida do VAR, enquanto que $e_{t}^{i}$ representa os erros estruturais provenientes da forma estrutural, SVAR. Os parâmetros do modelo estrutural SVAR foram estimados por Máxima Verossimilhança (ML Estimation) utilizando um Scoring Algorithm, o qual é descrito em detalhes em Amisano e Giannini (1997). ${ }^{4}$

Uma vez que os parâmetros do modelo estrutural tenham sido recuperados, é possível então obter as funções de resposta a impulso ortogonais dos produtos estaduais a um choque de $1 \%$ na taxa de juros. A próxima seção apresenta estes resultados.

\section{FUNÇÕES DE IMPULSO-RESPOSTA ESTADUAIS}

A Figura 1 apresenta as funções de resposta a impulso para os estados, a qual relaciona a resposta do índice de produção industrial a um choque de um $1 \%$ na taxa de juros.

A fim de facilitar a comparação entre as respostas dos produtos dos estados a um choque na taxa de juros, a Tabela 3 apresenta, em valores absolutos, as seguintes medidas de intensidade: a maior resposta apresentada pelos estados, o acumulado até a menor resposta, até o décimo período, até o vigésimo período, até o trigésimo período, e até o quadragésimo período. Os estados na tabela estão ordenados em ordem decrescente pelo valor absoluto da maior resposta em termos absolutos.

Tabela 3: Respostas Acumuladas (em valor absoluto) dos Produtos Estaduais a um choque de 1\% na Taxa de Juros (\%)

\begin{tabular}{|c|c|c|c|c|c|c|}
\hline UF & Resposta Máxima & $\begin{array}{c}\text { Resposta } \\
\text { Acumulada } \\
\text { Máxima }\end{array}$ & $\begin{array}{c}\text { Resposta } \\
\text { Acumulada até } \\
\text { o } 10^{\circ} \text { período }\end{array}$ & $\begin{array}{c}\text { Resposta } \\
\text { Acumulada até } \\
\text { o } 20^{\circ} \text { período }\end{array}$ & $\begin{array}{c}\text { Resposta } \\
\text { Acumulada até } \\
\text { o } 30^{\circ} \text { período }\end{array}$ & $\begin{array}{c}\text { Resposta } \\
\text { Acumulada até } \\
\text { o } 40^{\circ} \text { período }\end{array}$ \\
\hline YAM & 0,058 & 0,058 & 0,128 & 0,138 & 0,146 & 0,151 \\
\hline YPE & 0,051 & 0,051 & 0,087 & 0,101 & 0,040 & 0,111 \\
\hline YGO & 0,026 & 0,026 & 0,062 & 0,090 & 0,108 & 0,119 \\
\hline YBA & 0,026 & 0,026 & 0,045 & 0,051 & 0,054 & 0,055 \\
\hline YSP & 0,025 & 0,025 & 0,047 & 0,058 & 0,064 & 0,066 \\
\hline YCE & 0,022 & 0,022 & 0,032 & 0,035 & 0,036 & 0,037 \\
\hline YPA & 0,012 & 0,029 & 0,037 & 0,037 & 0,037 & 0,037 \\
\hline YMG & 0,008 & 0,008 & 0,016 & 0,017 & 0,018 & 0,018 \\
\hline YRJ & 0,006 & 0,006 & 0,014 & 0,016 & 0,017 & 0,017 \\
\hline YRS & 0,006 & 0,006 & 0,047 & 0,073 & 0,086 & 0,093 \\
\hline YPR & 0,006 & 0,006 & 0,025 & 0,035 & 0,108 & 0,043 \\
\hline YSC & 0,002 & 0,009 & 0,020 & 0,032 & 0,038 & 0,041 \\
\hline YES & 0,002 & 0,010 & 0,016 & 0,027 & 0,033 & 0,036 \\
\hline
\end{tabular}

Fonte: Elaboração dos autores. Nota: Todas as estatísticas acima são apresentadas em valores absolutos.

Os resultados apresentados na Tabela 3 mostram que, tanto no curto prazo, quanto no longo prazo, os estados tendem a ter reações assimétricas a choques na política monetária. Contudo, observa-se que não foi encontrado um padrão a partir do qual fosse possível comparar a intensidade de respostas agrupando os estados por grandes regiões geográficas para o período analisado. Esse resultado não

\footnotetext{
${ }^{4} \mathrm{O}$ software JMULTI foi utilizado para as estimações dos modelos. Os resultados das estimações estão à disposição dos interessados mediante solicitação junto aos autores.
} 


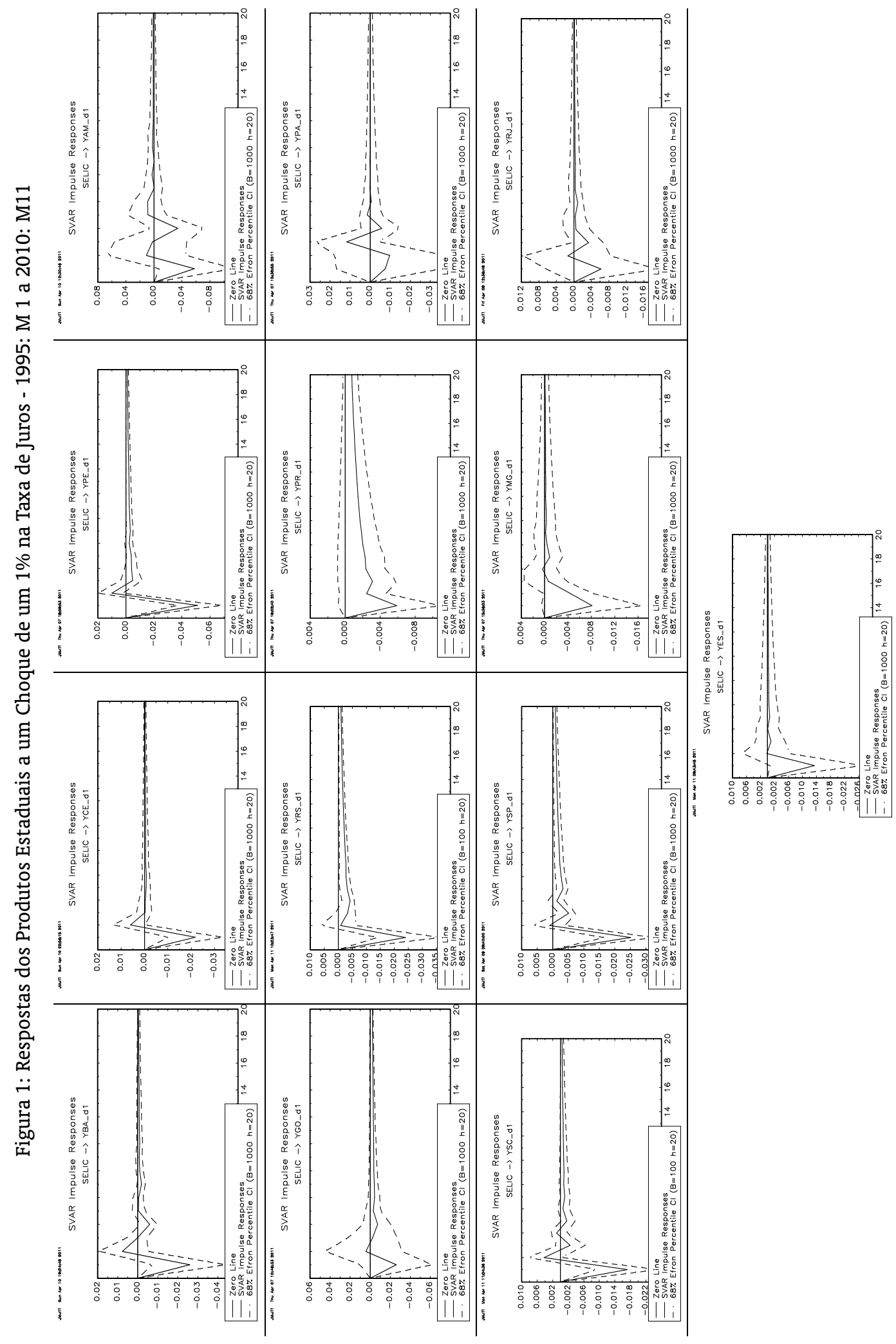


corrobora com o evidenciado por Araújo Jr. (2004), o qual observa que os estados da Região Sul, comparativamente aos estados da Região Nordeste, tendem a reagir mais intensamente a choques na política monetária. Por outro lado, os nossos resultados podem estar indicando que estados que não pertencem a uma mesma grande região tem características produtivas mais parecidas, relativo aos estados da sua região. Portanto, a semelhança dos estados quanto a sua matriz industrial e nível de desenvolvimento financeiro, por exemplo, deve ser mais importante para explicar se os estados apresentam reações simétricas à política monetária, relativo ao fator geográfico, à sua proximidade geográfica de outros estados.

Com base nos impulsos - reposta, destacando-se os estados com as maiores e menores respostas em reação a um aumento de $1 \%$ na taxa de juros, tem-se que o Estado do Amazonas foi o que se apresentou mais sensivel a choques monetários. O estado, para o qual se registrou uma queda de até $0,058 \%$ no seu produto, chega a ser quase trinta vezes maior que a observada para os Estados de Santa Catarina e Espírito Santos (IR de 0,002\%), estados com as menores reações. Seguindo o Estado do Amazonas está o estado de Pernambuco (IR de $0,051 \%$ ), com a segunda maior reação à política monetária. A maior reação de todos os demais estados foi inferior a $0,026 \%$.

Baseando-se nas respostas dos estados no longo prazo, com base na reposta acumulada até o quadragésimo período, constata-se que este cenário muda um pouco. O Estado do Amazonas continua liderando o ranking, com a maior resposta acumulada, em torno de $0,15 \%$. Mas, o Estado de Goiás passa a ser o segundo colocado, com um impulso resposta acumulado de aproximadamente $0,119 \%$, seguido do Estado de Pernambuco, com uma resposta acumulado de $0,111 \%$. No longo prazo, os Estados de Minas Gerais e Rio de Janeiro são os estados que responde menos intensamente a choques monetários, com um IR acumulado de $0,018 \%$ e $0,017 \%$, respectivamente.

Os resultados ainda mostram que a maior queda registrada para os estados foi entre o primeiro e o terceiro período, indicando que choques monetários impactam o produto no curto prazo. Uma vez que os resultados acima indicam que as economias estaduais tendem a responder de maneira assimétrica a choques na política monetária, a questão principal passa a ser a identificação dos fatores que explicam essa heterogeneidade. A seguir são apresentadas possíveis razões identificadas na literatura que justificam o evidenciado para a economia Brasileira.

\section{PORQUE AS ECONOMIAS TENDEM A REAGIR DIFERENTEMENTE A CHOQUES MONE- TÁRIOS}

A repercussão da política monetária sobre o produto dos estados pode ser amplificada ou minimizada, dependendo das características produtivas, do desenvolvimento financeiro, e de outros fatores sociais e demográficos que diferenciam as economias estaduais. Nesse sentido, a literatura econômica identifica alguns canais de transmissão da política monetária sobre a economia, que podem ajudar a responder por que os estados brasileiros reagem assimetricamente à política monetária.

\subsection{Canais de transmissão da política monetária}

Entre os fatores econômicos que podem explicar porque algumas economias tendem a reagir de forma mais intensa a choques monetários, estão dois canais de transmissão da política monetária sobre o produto que são bem explorados pela literatura, o canal da taxa de juros e o canal do crédito. 0 primeiro canal, tradicionalmente examinado pelos economistas, pode ser entendido a partir da relação negativa que existe entre a taxa de juros e o montante de investimentos de uma economia. Desse modo, se uma política monetária contracionista é implementada, elevando assim a taxa de juros do país, os investimentos são desestimulados pelo aumento do custo do capital e, consequentemente, haverá um decrescimento na produção. Considerando tudo o mais constante, é possível que choques monetários tenham um maior impacto nas economias que são mais dependentes de setores onde a taxa 
de juros representa uma regra importante na determinação do preço final dos produtos e dos custos de produção Carlino e Defina (1998). Esse canal sugere, portanto, que a composição industrial das regiões pode explicar, pelo menos em parte, as assimetrias das respostas dos produtos estaduais a política monetária.

Reforçando ou minimizando os efeitos do canal da taxa de juros, características do mercado financeiro regional também podem explicar porque algumas economias reagem mais ou menos intensamente a choques monetários, através do canal de crédito. A base de explicação desse canal respalda-se nas imperfeições do mercado de crédito - seleção adversa e risco moral - que diferenciam a dinâmica desse mercado entre as regiões (Bernanke, 1986). De acordo com esse canal, em um período de contração monetária, as restrições ao crédito tendem a aumentar, tornando o crédito mais difícil para aquelas empresas que não podem garantir um colateral para o empréstimo bancário. Por outro lado, os bancos também dependem da captação de recursos no mercado financeiro e das operações de empréstimos, e uma política contracionista tende a reduzir as reservas bancárias e os depósitos bancários (Bernanke e Gertler, 1989). Consequentemente, de acordo com esse canal, deve-se esperar que as regiões que apresentam maior concentração de micro e pequenas empresas e bancos de pequeno porte, os quais são mais sensíveis a captação de recursos financeiros, ou um sistema financeiro menos desenvolvido, uma política monetária contracionista venha a ter uma maior repercussão negativa sobre o produto.

Além desses canais, buscando agregar informações para explicar a heterogeneidade da repercussão da política monetária sobre diferentes economias, recentemente outras características regionais vêm sendo exploradas. Vale salientar, porém, que esses canais não devem ser analisados de forma isolada, pois são interdependentes aos canais de crédito e da taxa de juros. Entre essas características regionais, estão fatores sócio-demográficos e do mercado de trabalho local, do mercado de habitação, da política fiscal e do governo local (Francis et alii, 2009). Nesse sentido, conforme sugere o "canal sóciodemográfico", é possível que as regiões mais densamente povoadas, i.e. grandes centros urbanos, por ofertarem maiores oportunidades e diversidade de emprego, sejam mais propensos a ter uma menor resposta em períodos de contração monetária. A questão é que regiões com essas características tendem a ter um mercado de trabalho mais dinâmico, pela maior diversidade de oportunidades de trabalho, o que possibilita migração dos trabalhadores dos setores mais afetados para os setores menos afetados em períodos de recessão. Além disso, a qualificação da população ocupada também pode explicar, ao menos em parte, as assimetrias de respostas das regiões a choques na política monetária. A idéia é que trabalhadores mais qualificados têm maiores chances de se manter no emprego em períodos de recessão, assegurando, assim, o seu nível de consumo. Como resultado, é possível que aquelas unidades geográficas com um maior estoque de capital humano, apresentem uma menor queda no seu produto, em termos relativos, em resposta a uma política contracionista.

Características da política fiscal local e da participação do governo na economia, também podem fazer com que as economias estaduais reajam assimetricamente à política monetária. Esse canal pode ser entendido a partir da observação das economias que dependem mais fortemente do governo, como por exemplo, aquelas que têm uma maior participação de servidores públicos no pessoal ocupado. De acordo com esse canal, tais economias devem reagir com uma menor intensidade e com alguma defasagem de tempo a choques monetários. Intuitivamente, espera-se que o setor público por ser mais rígido que o setor privado, o ciclo de negócios dessas economias, que tem uma maior participação do governo, seja mais acíclico, comparativamente com aquelas que dependem em menor escala do governo (Francis et alii, 2009).

Além desses, Iacoviello e Minetti (2008) sugerem o canal da habitação, o qual pode ser associado com o canal de juros e com o canal de crédito, e com as características fiscais e da política habitacional (participação do governo na economia). A base de explicação desse canal está no efeito multiplicador que representa o setor de habitação ou da indústria da construção civil para uma economia. Em geral, esse setor tem uma significativa participação nos produtos regionais e, também, no emprego local, e, sendo assim, as regiões que possuem esse setor menos desenvolvido ou mais dependente da capitação de recursos no mercado financeiro, devem ter seus produtos mais fortemente influenciados. 


\subsection{Testando os canais de transmissão}

Buscando levantar evidências da importância dos referidos canais de transmissão da política monetária sobre os produtos estaduais, vários modelos de regressão (cross -section) foram estimados, regredindo uma medida das respostas dos produtos estaduais a choques monetários em função de variáveis que representam esses canais. O modelo empírico pode ser representado por:

$$
I R F_{j}=\beta_{0}+\beta_{1} x_{1 j}+\beta_{2} x_{2 j}+\beta_{3} x_{3 j}+u_{j}
$$

onde $I R F_{j}$ é a resposta do produto do estado $j$, extraída dos modelos Vetoriais Auto-regressivos Estruturais (SVAR) estimados. A equação 4 é estimada pelo método de mínimos quadrados ordinários, considerando duas especificações para a variável dependente: a maior resposta (em termos absolutos) dos estados; e, para captar uma tendência de longo prazo, a resposta acumulada até o quadragésimo período. 0 vetor de variáveis explicativas " $x_{1 j}$ ", que representa o canal da taxa de juros, inclui características da estrutura produtiva dos estados. 0 vetor " $x_{2 j}$ " inclui variáveis da estrutura financeira e do porte dos estabelecimentos localizados nos estados, os quais buscam captar a importância do canal da taxa de crédito para explicar a reação dos estados a choques monetários. E, finalmente, o vetor " $x_{3 j}$ ", engloba variáveis demográficas e do mercado de trabalho.

As Tabelas A-5 e A-6, ambas no Apêndice, apresentam uma descrição das variáveis utilizadas na estimação da equação 4 e algumas estatísticas descritivas destas variáveis, respectivamente.

Entre os modelos estimados, o modelo com a variável dependente sendo o valor absoluto da maior resposta negativa dos estados, foi o que apresentou os melhores resultados e, portanto, a análise a seguir baseia-se nesse modelo. Os resultados encontram-se na Tabela 4, a qual apresenta diferentes versões do modelo estimado, com variáveis explicativas que representam os canais de transmissão da política monetária. Os resultados dos demais modelos estimados, tendo como variável dependente a resposta acumulada dos estados até o quadragésimo período, são reportados no Apêndice (Tabela A-7). Estas estimações podem ser utilizadas para verificar a robustez dos modelos estimados. Em linhas gerais, os resultados dos modelos estimados, considerando as respostas acumuladas até o quadragésimo período, apresentam resultados bem parecidos aos modelos estimados a partir da maior resposta dos estados, no que se refere a significância e ao sinal dos coeficientes. Porém, deve-se ressaltar que uma limitação importante dos resultados desta segunda parte consiste no reduzido número de observações disponíveis (apenas 13 observações), o que prejudica nas estimações dos intervalos de confiança e na realização de testes de hipóteses.

Considerando a heterogeneidade da composição produtiva da nossa amostra, o erro-padrão dos coeficientes estimados foram corrigidos pelo critério de White (1980), sendo, portanto, robusto para a presença de heterocedasticidade nos modelos.

Os resultados deste exercício são reportados na Tabela 4. Uma análise destes nos permitem extrair algumas conclusões interessantes. A primeira diz respeito à importância da estrutura produtiva na determinação do impacto da política monetária sobre os Estados brasileiros. Os resultados mostram que aqueles estados com maior participação de estabelecimentos industriais e da indústria extrativista devem reagir menos intensamente à política monetária, mas o coeficiente da participação dos estabelecimentos da indústria da transformação não se apresentou estatisticamente significante. Este resultado não corrobora os pressupostos tradicionais do canal da taxa de juros, o qual sugere que as economias com um maior percentual de estabelecimentos da indústria de manufaturas, devem apresentar maiores respostas à política monetária. Resultado este encontrado por Owyang e Wall (2009) para regiões da Europa, os quais, com o mesmo objetivo de pesquisa, evidenciaram, para alguns dos modelos estimados, que as regiões com um maior setor de manufaturas tendem a reagir mais intensamente a choques monetários. Por outro lado, os nossos resultados mostram que estados com maior presença da indústria extrativa tendem a responder menos intensamente a choques monetários. Isto revela o fato de que este setor industrial possui menor dependência da taxa de juros doméstica para seu desempenho ao longo dos ciclos econômicos. 
A segunda diz respeito ao fato de que os produtos dos estados que possuem maiores relações com a economia externa, medido pelo grau de abertura comercial, tendem a reagir menos intensamente a choques monetários. Mais uma vez, a idéia é que quanto maior o grau de abertura comercial menor seria a dependência da economia estadual a desdobramentos da política monetária doméstica e, portanto, os impactos de choques monetários seriam mais reduzidos. Além disto, podemos concluir que o produto dos estados com um maior volume de depósitos bancários apresenta maiores reações a política monetária, comparativamente a aqueles que possuem um menor volume de depósitos bancários. Este resultado condiz com as hipóteses levantadas pelo canal de crédito, as quais indicam que as economias dos estados que têm um sistema financeiro mais dependente do mercado de crédito, com um maior volume de transações financeiras, são mais fortemente afetados em períodos de contração monetária, em função da redução da liquidez na economia e, portanto, quanto o crédito é mais restrito. Por outro lado, as variáveis que mensuram o porte das empresas, medidas pelo pessoal ocupado, não são consistentes com o canal de crédito. A princípio era esperado que os sinais para as variáveis de porte das empresas fossem negativos, pois eles refletiriam o pressuposto de que estados com maior presença de grandes empresas seriam menos afetados por choques contracionistas, por serem as empresas maiores mais hábeis de oferecerem colateral nos empréstimos, ou serem capazes de auto-financiamento. Contudo, o sinal positivo obtido em nossas estimações pode estar refletindo a idéia de que as empresas maiores são as que acabam tendo mais acesso ao mercado financeiro e, portanto, apresentam maior dependência dos desdobramentos da política monetária. Por conseguinte, estados com maior presença de empresas maiores seriam mais fortemente afetados. Esta observação parte do princípio de que as operações de crédito no Brasil são concentradas em operações de mais curto prazo e, portanto, mais dependentes da evolução das taxas de juros no curto prazo. Talvez, para o Brasil, estas variáveis não sejam boas proxies para avaliar a capacidade das empresas de manter o seu nível de produção em períodos de recessão. Ressalta-se, porém, que para as regiões da Europa, Owyang e Wall (2009) obtiveram indicações, para alguns dos modelos estimados, de que as regiões com uma maior concentração de grandes bancos tendem a apresentar menores reações a choques monetários.

Por fim, no que diz respeito ao canal sócio-demográfico, os resultados apontam que os produtos dos estados com uma maior densidade demográfica, maior índice de diversidade e maior estoque de capital humano apresentam menores impactos em resposta a um choque contracionista da política monetária. Estes resultados, portanto, corroboram os pressupostos do canal sócio-demográfico. Por outro lado, ao contrário do esperado, os produtos dos estados com um maior percentual de funcionários públicos apresentam tendem a responder mais intensamente a choques na taxa de juros.

\section{CONSIDERAÇÕES FINAIS}

Este artigo investigou, em um primeiro momento, se choques na política monetária apresentam impactos diferenciados sobre o produto dos estados brasileiros. A análise foi baseada nas funções de resposta a impulso ortogonais obtidas a partir da estimação de modelos SVARs para cada um dos estados considerados na análise. Os resultados apontaram para a existência de impactos diferenciados em termos de intensidade das respostas dos produtos estaduais a choques monetários, com alguns estados respondendo com maior intensidade do que outros. Por exemplo, observa-se que o produto do Estado do Amazonas (estado que apresentou a maior queda a choques na política monetária), chega a ser quase trinta vezes maior que a observada para os Estados de Santa Catarina e Espírito Santos (estados com as menores quedas). Contudo, vale salientar, que não foi encontrado um padrão que pudesse comparar a intensidade de respostas de acordo com as grandes regiões do país. Portanto, a similaridade da estrutura industrial, do desenvolvimento financeiro e sócio-demográfico parecem importar mais, na definição das respostas dos produtos estaduais a choques monetários, do que a proximidade geográfica. Adicionalmente, a partir de uma análise do comportamento de longo prazo das reações dos estados, o 


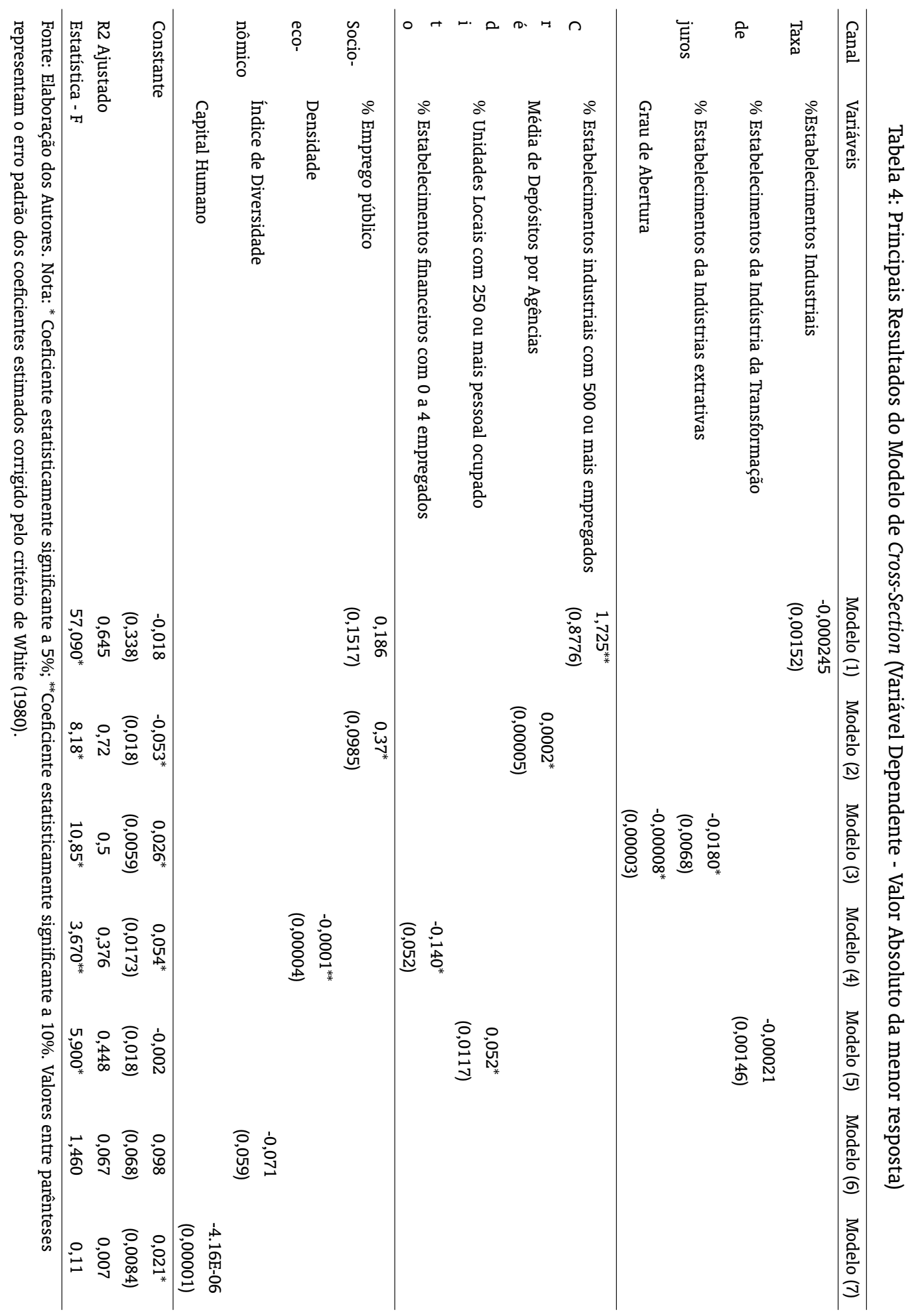


Estado do Amazonas continua liderando o ranking, com a maior resposta acumulada, e os Estados de Minas Gerais e Rio de Janeiro são os estados que responde menos intensamente a choques monetários.

Diante dos resultados de que os estados brasileiros tendem a ter reações assimétricas a choques na política monetária, a segunda parte deste artigo investigou as razões que explicariam tais impactos diferenciados da política monetária. Isto foi feito com base nos resultados das funções de resposta à impulso e a partir da estimação de modelos de regressão que relacionaram uma medida da resposta dos produtos estaduais a choques monetários a um conjunto de indicadores que representam três canais de transmissão da política monetária, quais sejam: o de crédito, o da taxa de juros, e o demográfico/mercado de trabalho.

Os resultados desta segunda parte da análise sugerem que elementos dos três canais acima acabam influenciando a intensidade das respostas dos produtos estaduais a choques monetários, o que oferece algum suporte para os canais analisados. Por exemplo, estados com uma maior indústria extrativista, com maior participação de indústria extrativa e com maior relação com o exterior acabam sendo menos afetados por choques contracionistas. Em conjunto, estes resultados oferecem suporte ao canal da taxa de juros. Por outro lado, estados com um maior volume de depósitos bancários, respondem mais intensamente a choques monetários, oferecendo suporte ao canal de crédito. Por fim, estados com maior densidade demográfica são menos afetados por choques contracionistas da política monetária. Em conjunto, estes resultados oferecem suporte à importância dos canais da taxa de juros, embora em menor grau, e do canal de crédito e do sócio-demográfico como potenciais explicações para os impactos diferenciados da política monetária sobre os produtos dos estados brasileiros.

Os resultados deste artigo sugerem, portanto, cautela na condução da política monetária do país, uma vez que a implementação de políticas que ignorem a diversidade econômica e social do país podem ter efeitos não desejáveis e podem aprofundar ainda mais as disparidades regionais do país.

\section{BIBLIOGRAFIA}

Amisano, G. \& Giannini, C. (1997). Topics in Structural VAR's. Springer, 2nd edition.

Araújo Jr., E. A. (2004). Medindo o impacto regional da politica monetária brasileira: Uma comparação entre as regiões nordeste e sul. Revista Econômica do Nordeste, 5(3):356-393.

Bernanke, B. (1986). Alternative explanations of the money-income correlation. Carnegie/Rochester Conference Series on Public Policy, 25:49-100.

Bernanke, B. \& Gertler, M. (1989). Agency costs, net worth, and business fluctuations. American Economic Review, 79:14-31.

Bertanha, M. \& Haddad, E. (2008). Efeitos regionais da política monetária no Brasil: Impactos e transbordamentos espaciais. Revista Brasileira de Economia, 62(1):3-29.

Carlino, G. \& Defina, R. (1998). The differential regional effects of monetary policy. Review of Economics and Statistics, 80(4):572-587.

Carlino, G. \& Defina, R. (1999). The differential regional effects of monetary policy: Evidence from the U.S. states. Journal of Regional Science, 39(2):339-358.

Carlino, G. \& Defina, R. (2000). Monetary policy and the U.S. and regions: some implications for european monetary union. In Regional Aspects of Monetary Policy in Europe, pages 123-134. Kluwer Academic Publishers.

Francis, N., Owyang, M. T., \& Sekhposyan, T. (2009). The local effects of monetary policy. Technical Report 2009-048A, Federal Reserve Bank of Saint Louis. 
Gerlach, S. \& Smets, F. (1995). The monetary transmission mechanism: Evidence from the G-7 countries. Technical Report 26, Bank for International Settlements.

Iacoviello, M. \& Minetti, R. (2008). The credit channel of monetary policy: Evidence from the housing market. Journal of Macroeconomics, 30(1):69-96.

Ivanov, V. \& Kilian, L. (2005). A practitioner's guide to lag order selection for VAR impulse response analysis. Studies in Nonlinear Dynamics and Econometrics, 9(1):1-34.

Minella, A. (2003). Monetary policy and inflation in Brazil (1975-2000): A VAR estimation. Revista Brasileira de Economia, 57(3):605-635.

Owyang, M. T. \& Wall, H. J. (2009). Regional VARs and the channels of monetary policy. Applied Economics Letters, 16(12):1191-1194.

Sims, C. (1980). Macroeconomics and reality. Econometrica, 48:1-49.

Vasconcelos, M. R. \& Fonseca, M. W. (2002). Política monetária no Brasil: Mecanismos de transmissão e impactos diferenciados nas regiões e estados da federação. In Anais da ANPEC-Nordeste, Fortaleza.

White, H. (1980). A heteroskedasticity-consistent covariance matrix estimator and a direct test for heteroskedasticity. Econometrica, 48(4):817-38. 


\section{A. APÊNDICE}

Tabela A-1: Resultados do Teste Kwiatkowski Phillips - Schmidt - Shin (KPSS) - Séries em primeira diferença

\begin{tabular}{cccccc}
\hline \multirow{2}{*}{ Variável } & \multirow{2}{*}{$\mathbf{N}^{\mathbf{*}}$ de Defasagens* } & \multirow{2}{*}{ Valor Calculado } & \multicolumn{3}{c}{ Valor Tabelado } \\
\cline { 4 - 6 } & & & $\mathbf{1 \%}$ & $\mathbf{5 \%}$ & $\mathbf{1 0 \%}$ \\
\hline SELIC & 2 & 0,0599 & 0,739 & 0,463 & 0,347 \\
\hline YAM & 1 & 0,0305 & 0,739 & 0,463 & 0,347 \\
\hline YBA & 2 & 0,0140 & 0,739 & 0,463 & 0,347 \\
\hline YBR & 2 & 0,0757 & 0,739 & 0,463 & 0,347 \\
\hline YCE & 2 & 0,0346 & 0,739 & 0,463 & 0,347 \\
\hline YES & 2 & 0,0251 & 0,739 & 0,463 & 0,347 \\
\hline YGO & 1 & 0,0193 & 0,739 & 0,463 & 0,347 \\
\hline YMG & 2 & 0,0275 & 0,739 & 0,463 & 0,347 \\
\hline YPA & 1 & 0,0665 & 0,739 & 0,463 & 0,347 \\
\hline YPE & 2 & 0,0376 & 0,739 & 0,463 & 0,347 \\
\hline YPR & 2 & 0,0638 & 0,739 & 0,463 & 0,347 \\
\hline YRJ & 2 & 0,0245 & 0,739 & 0,463 & 0,347 \\
\hline YRS & 2 & 0,0620 & 0,739 & 0,463 & 0,347 \\
\hline YSC & 2 & 0,0250 & 0,739 & 0,463 & 0,347 \\
\hline YSP & 2 & 0,1236 & 0,739 & 0,463 & 0,347 \\
\hline
\end{tabular}

Fonte: Elaboração Própria. *O número de lags é baseado no critério de Bandwidth definido por $(4(\mathrm{~T} / 100)) 2 / 9$. 


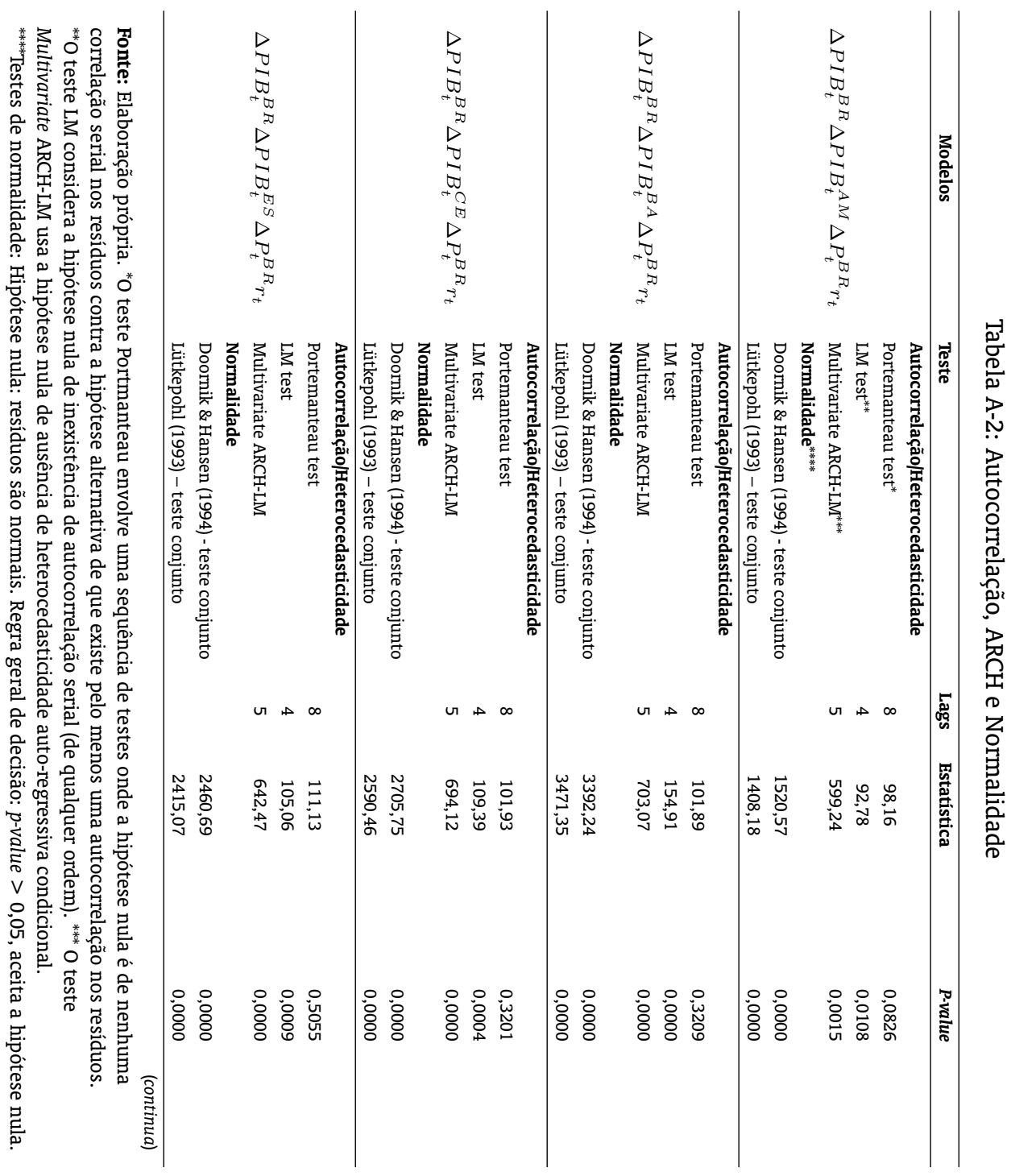




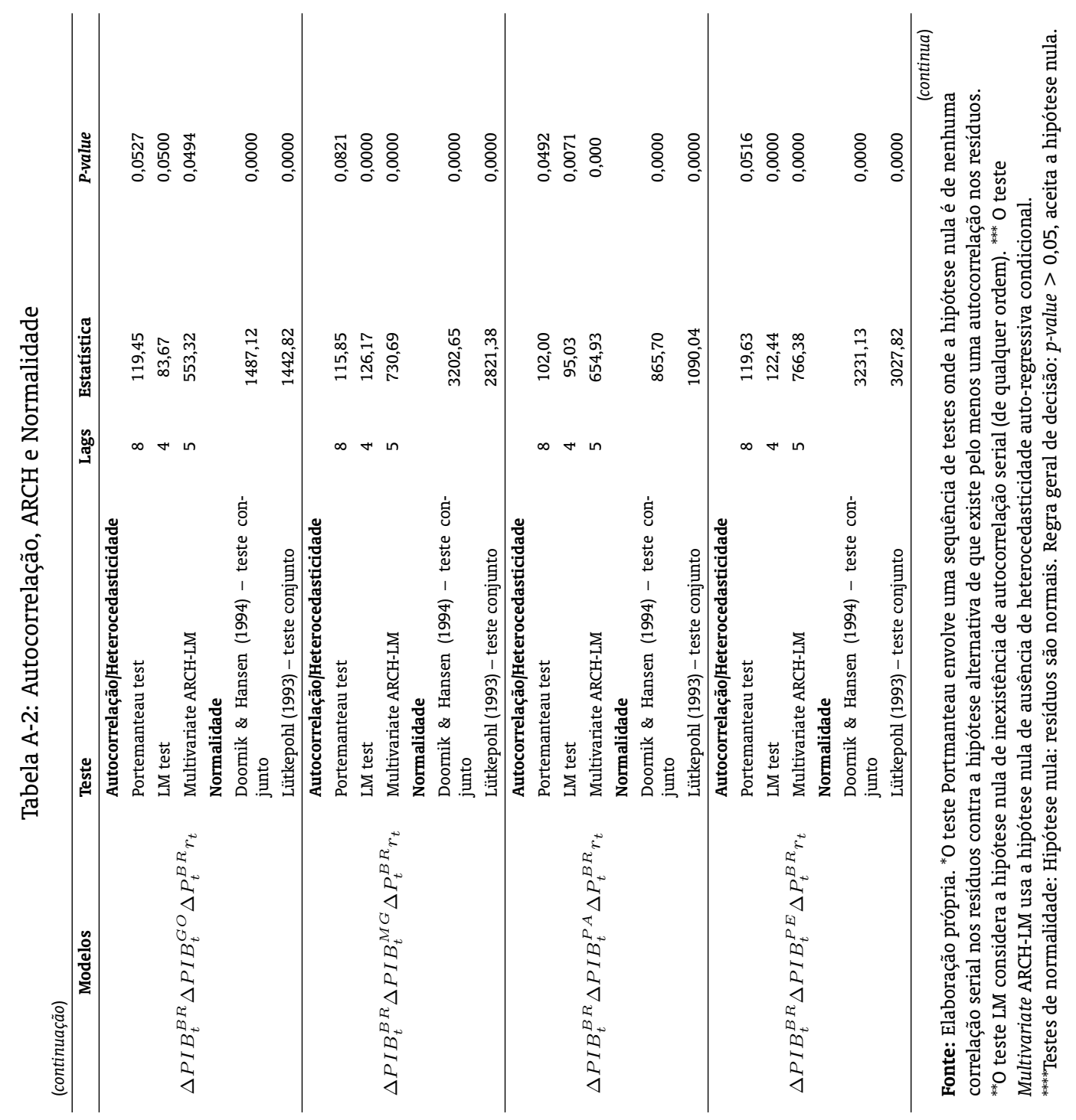




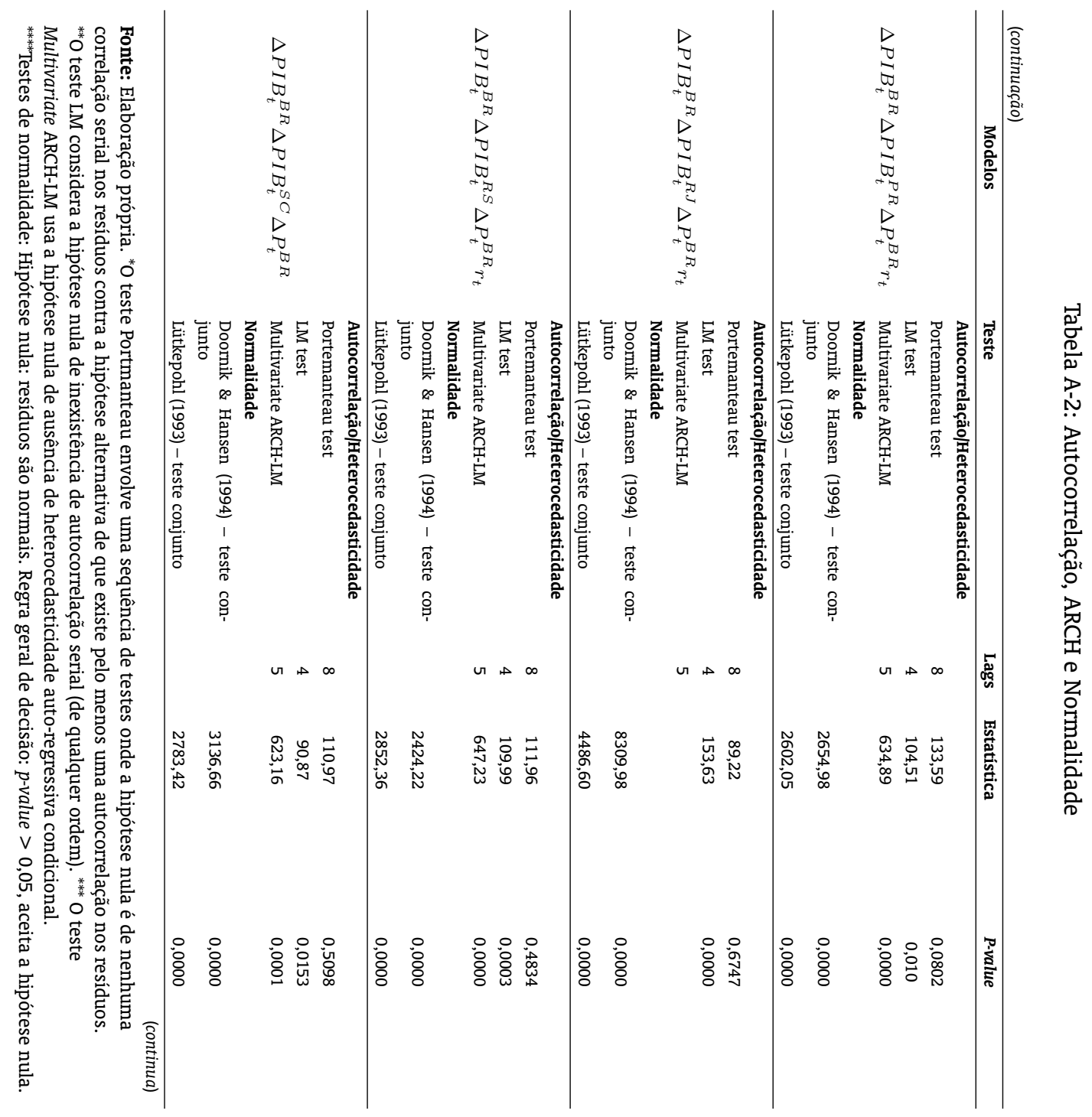




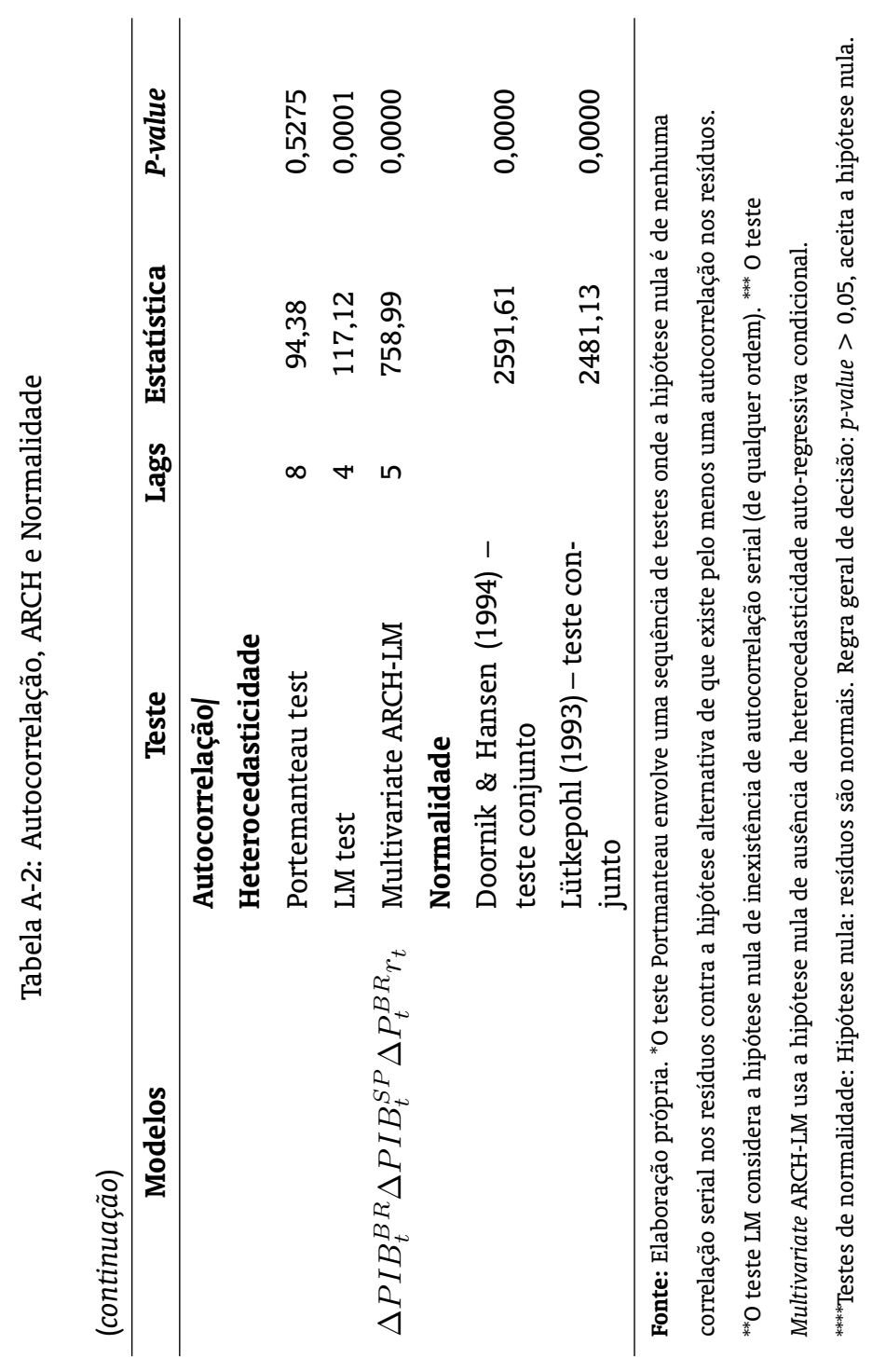


Tabela A-3: Testes de Autocorrelação dos resíduos

\begin{tabular}{|c|c|c|c|c|c|}
\hline Modelos & Componentes & Portemanteau* & P-value & Ljung-Box ${ }^{* *}$ & P-value \\
\hline \multirow{4}{*}{$\Delta P I B_{t}^{B R} \Delta P I B_{t}^{A M} \Delta P_{t}^{B R} r_{t}$} & $1^{\circ}$ Componente & 12,96 & 0,99 & 16,04 & 0,99 \\
\hline & $2^{\circ}$ Componente & 37,28 & 0,41 & 48,11 & 0,09 \\
\hline & $3^{\circ}$ Componente & 26,33 & 0,88 & 31,41 & 0,69 \\
\hline & $4^{\circ}$ Componente & 62,27 & 0,00 & 77,49 & 0,00 \\
\hline \multirow{4}{*}{$\Delta P I B_{t}^{B R} \Delta P I B_{t}^{B A} \Delta P_{t}^{B R} r_{t}$} & $1^{\circ}$ Componente & 26,69 & 0,87 & 30,41 & 0,73 \\
\hline & $2^{\circ}$ Componente & 36,82 & 0,43 & 39,77 & 0,31 \\
\hline & $3^{\circ}$ Componente & 58,76 & 0,01 & 66,53 & 0,00 \\
\hline & $4^{\circ}$ Componente & 44,64 & 0,15 & 49,33 & 0,07 \\
\hline \multirow{4}{*}{$\Delta P I B_{t}^{B R} \Delta P I B_{t}^{C E} \Delta P_{t}^{B R} r_{t}$} & $1^{\circ}$ Componente & 29,48 & 0,77 & 33,35 & 0,59 \\
\hline & $2^{\circ}$ Componente & 36,88 & 0,43 & 41,66 & 0,24 \\
\hline & $3^{\circ}$ Componente & 61,20 & 0,01 & 69,45 & 0,00 \\
\hline & $4^{\circ}$ Componente & 49,04 & 0,07 & 54,19 & 0,03 \\
\hline \multirow{4}{*}{$\Delta P I B_{t}^{B R} \Delta P I B_{t}^{E S} \Delta P_{t}^{B R} r_{t}$} & $1^{\circ}$ Componente & 26,88 & 0,86 & 30,35 & 0,73 \\
\hline & $2^{\circ}$ Componente & 45,93 & 0,12 & 50,72 & 0,05 \\
\hline & $3^{\circ}$ Componente & 58,56 & 0,01 & 66,33 & 0,00 \\
\hline & $4^{\circ}$ Componente & 47,24 & 0,09 & 52,35 & 0,04 \\
\hline \multirow{4}{*}{$\Delta P I B_{t}^{B R} \Delta P I B_{t}^{G O} \Delta P_{t}^{B R} r_{t}$} & $1^{\circ}$ Componente & 14,79 & 0,99 & 18,29 & 0,99 \\
\hline & $2^{\circ}$ Componente & 44,49 & 0,16 & 53,20 & 0,03 \\
\hline & $3^{\circ}$ Componente & 20,98 & 0.98 & 24,96 & 0,92 \\
\hline & $4^{\circ}$ Componente & 84,90 & 0,00 & 103,68 & 0,00 \\
\hline \multirow{4}{*}{$\Delta P I B_{t}^{B R} \Delta P I B_{t}^{M G} \Delta P_{t}^{B R} r_{t}$} & $1^{\circ}$ Componente & 26,51 & 0,88 & 29,76 & 0,96 \\
\hline & $2^{\circ}$ Componente & 21,51 & 0,97 & 23,99 & 0,94 \\
\hline & $3^{\circ}$ Componente & 60,94 & 0,00 & 68,89 & 0,00 \\
\hline & $4^{\circ}$ Componente & 45,36 & 0,14 & 50,05 & 0,06 \\
\hline \multirow{4}{*}{$\Delta P I B_{t}^{B R} \Delta P I B_{t}^{P A} \Delta P_{t}^{B R} r_{t}$} & $1^{\circ}$ Componente & 14,15 & 0,99 & 17,42 & 0,99 \\
\hline & $2^{\circ}$ Componente & 20,64 & 0,98 & 25,35 & 0,91 \\
\hline & $3^{\circ}$ Componente & 23,05 & 0,95 & 27,83 & 0,83 \\
\hline & $4^{\circ}$ Componente & 89,97 & 0,00 & 109,32 & 0,00 \\
\hline \multirow{4}{*}{$\Delta P I B_{t}^{B R} \Delta P I B_{t}^{P E} \Delta P_{t}^{B R} r_{t}$} & $1^{\circ}$ Componente & 25,71 & 0,98 & 28,96 & 0,79 \\
\hline & $2^{\circ}$ Componente & 41,13 & 0,26 & 44,89 & 0,15 \\
\hline & $3^{\circ}$ Componente & 71,50 & 0,00 & 81,21 & 0,00 \\
\hline & $4^{\circ}$ Componente & 47,74 & 0,09 & 51,94 & 0,04 \\
\hline \multirow{4}{*}{$\Delta P I B_{t}^{B R} \Delta P I B_{t}^{P R} \Delta P_{t}^{B R} r_{t}$} & $1^{\circ}$ Componente & 23,47 & 0,95 & 26,57 & 0,87 \\
\hline & $2^{\circ}$ Componente & 82,89 & 0,00 & 90,48 & 0,00 \\
\hline & $3^{\circ}$ Componente & 54,05 & 0,03 & 60,97 & 0,01 \\
\hline & $4^{\circ}$ Componente & 48,62 & 0,08 & 54,11 & 0,03 \\
\hline \multirow{4}{*}{$\Delta P I B_{t}^{B R} \Delta P I B_{t}^{R J} \Delta P_{t}^{B R} r_{t}$} & $1^{\circ}$ Componente & 26,15 & 0,89 & 29,67 & 0,76 \\
\hline & $2^{\circ}$ Componente & 16,36 & 0,99 & 17,69 & 0,99 \\
\hline & $3^{\circ}$ Componente & 55,60 & 0,02 & 62,96 & 0,00 \\
\hline & $4^{\circ}$ Componente & 41,65 & 0,24 & 46,07 & 0,12 \\
\hline
\end{tabular}

Fonte: Elaboração própria. *O teste Portmanteau envolve uma sequência de testes onde a hipótese nula é de nenhuma correlação serial nos resíduos contra a hipótese alternativa de que existe pelo menos uma autocorrelação nos resíduos. **O Teste Ljung-box testa a hipótese nula de que existe autocorrelação serial dos resíduos. Regra geral de decisão: $p$-value $>0,05$, aceita a hipótese nula. 
Tabela A-3: Testes de Autocorrelação dos resíduos

(continuação)

\begin{tabular}{|c|c|c|c|c|c|}
\hline Modelos & Componentes & Portemanteau* & P-value & Ljung-Box ${ }^{* *}$ & P-value \\
\hline \multirow{4}{*}{$\Delta P I B_{t}^{B R} \Delta P I B_{t}^{R S} \Delta P_{t}^{B R} r_{t}$} & $1^{\circ}$ Componente & 23,19 & 23,19 & 26,27 & 0,88 \\
\hline & $2^{\circ}$ Componente & 30,5 & 30,50 & 34,77 & 0,53 \\
\hline & $3^{\circ}$ Componente & 55,32 & 55,32 & 62,42 & 0,00 \\
\hline & $4^{\circ}$ Componente & 49,61 & 49,61 & 54,69 & 0,02 \\
\hline \multirow{4}{*}{$\Delta P I B_{t}^{B R} \Delta P I B_{t}^{S C} \Delta P_{t}^{B R} r_{t}$} & $1^{\circ}$ Componente & 23,27 & 23,27 & 26,37 & 0,88 \\
\hline & $2^{\circ}$ Componente & 47,98 & 47,98 & 54,39 & 0,03 \\
\hline & $3^{\circ}$ Componente & 56,34 & 56,34 & 63,55 & 0,00 \\
\hline & $4^{\circ}$ Componente & 52,94 & 52,94 & 58,73 & 0,01 \\
\hline \multirow{4}{*}{$\Delta P I B_{t}^{B R} \Delta P I B_{t}^{S P} \Delta P_{t}^{B R} r_{t}$} & $1^{\circ}$ Componente & 20,49 & 20,49 & 23,03 & 0,95 \\
\hline & $2^{\circ}$ Componente & 23,50 & 23,50 & 26,49 & 0,88 \\
\hline & $3^{\circ}$ Componente & 60,71 & 60,71 & 68,68 & 0,00 \\
\hline & $4^{\circ}$ Componente & 45,47 & 45,47 & 50,19 & 0,06 \\
\hline
\end{tabular}

Fonte: Elaboração própria. *O teste Portmanteau envolve uma sequência de testes onde a hipótese nula é de nenhuma correlação serial nos resíduos contra a hipótese alternativa de que existe pelo menos uma autocorrelação nos resíduos.

**O Teste Ljung-box testa a hipótese nula de que existe autocorrelação serial dos resíduos. Regra geral de decisão: $p$-value $>0,05$, aceita a hipótese nula. 
Tabela A-4: Testes de Normalidade: Jarque-Bera e ARCH-LM

\begin{tabular}{|c|c|c|c|c|}
\hline Modelo & Teste & Componente & Estatística & P-value $\left(\chi^{2}\right)$ \\
\hline \multirow{8}{*}{$\Delta P I B_{t}^{B R} \Delta P I B_{t}^{A M} \Delta P_{t}^{B R} r_{t}$} & \multirow{4}{*}{ Jarque-Bera* } & 1 & 687,65 & 0,0000 \\
\hline & & 2 & 24,93 & 0,0000 \\
\hline & & 3 & 672,23 & 0,0000 \\
\hline & & 4 & 0,13 & 0,9370 \\
\hline & \multirow{4}{*}{ ARCH-LM" ${ }^{* *}$} & 1 & 19,73 & 0,2326 \\
\hline & & 2 & 19,81 & 0,2290 \\
\hline & & 3 & 12,26 & 0,7258 \\
\hline & & 4 & 21,58 & 0,1573 \\
\hline \multirow{8}{*}{$\Delta P I B_{t}^{B R} \Delta P I B_{t}^{B A} \Delta P_{t}^{B R} r_{t}$} & \multirow{4}{*}{ Jarque-Bera } & 1 & 1487,73 & 0,0000 \\
\hline & & 2 & 1171,82 & 0,0000 \\
\hline & & 3 & 184,48 & 0,00001 \\
\hline & & 4 & 1811,44 & 0,0000 \\
\hline & \multirow{4}{*}{ ARCH-LM } & 1 & 14,05 & 0,5948 \\
\hline & & 2 & 8,43 & 0,9350 \\
\hline & & 3 & 11,64 & 0,7686 \\
\hline & & 4 & 30,93 & 0,0137 \\
\hline \multirow{8}{*}{$\Delta P I B_{t}^{B R} \Delta P I B_{t}^{C E} \Delta P_{t}^{B R} r_{t}$} & \multirow{4}{*}{ Jarque-Bera } & 1 & 1528,54 & 0,0000 \\
\hline & & 2 & 3,77 & 0,1519 \\
\hline & & 3 & 217,89 & 0,0000 \\
\hline & & 4 & 738,36 & 0,0000 \\
\hline & \multirow{4}{*}{ ARCH-LM } & 1 & 23,75 & 0,0952 \\
\hline & & 2 & 22,99 & 0,1138 \\
\hline & & 3 & 8,69 & 0,9254 \\
\hline & & 4 & 35,02 & 0,0040 \\
\hline \multirow{8}{*}{$\Delta P I B_{t}^{B R} \Delta P I B_{t}^{E S} \Delta P_{t}^{B R} r_{t}$} & \multirow{4}{*}{ Jarque-Bera } & 1 & 799,343 & 0,0000 \\
\hline & & 2 & 62,87 & 0,0000 \\
\hline & & 3 & 224,99 & 0,0000 \\
\hline & & 4 & 1622,40 & 0,0000 \\
\hline & \multirow{4}{*}{ ARCH-LM } & 1 & 20,83 & 0,1853 \\
\hline & & 2 & 30,46 & 0,0157 \\
\hline & & 3 & 7,44 & 0,9639 \\
\hline & & 4 & 29,75 & 0,0193 \\
\hline \multirow{8}{*}{$\Delta P I B_{t}^{B R} \Delta P I B_{t}^{G O} \Delta P_{t}^{B R} r_{t}$} & \multirow{4}{*}{ Jarque-Bera } & 1 & 862,94 & 0,0000 \\
\hline & & 2 & 0,56 & 0,7557 \\
\hline & & 3 & 596,73 & 0,0000 \\
\hline & & 4 & 0,16 & 0,9231 \\
\hline & \multirow{4}{*}{ ARCH-LM } & 1 & 16,39 & 0,4259 \\
\hline & & 2 & 29,11 & 0,0232 \\
\hline & & 3 & 15,20 & 0,5098 \\
\hline & & 4 & 25,69 & 0,0585 \\
\hline
\end{tabular}

Fonte: Elaboração própria. ${ }^{*}$ Testes de normalidade: Hipótese nula: resíduos são normais. ${ }^{* *} \mathrm{O}$ teste $A R C H-L M$ usa a hipótese nula de ausência de heterocedasticidade auto-regressiva condicional. Regra geral de decisão: p-value $>0,05$, aceita a hipótese nula. 
Tabela A-4: Testes de Normalidade: Jarque-Bera e ARCH-LM

(continuação)

\begin{tabular}{|c|c|c|c|c|}
\hline Modelo & Teste & Componente & Estatística & P-value $\left(\chi^{2}\right)$ \\
\hline \multirow{8}{*}{$\Delta P I B_{t}^{B R} \Delta P I B_{t}^{M G} \Delta P_{t}^{B R} r_{t}$} & \multirow{4}{*}{ Jarque-Bera } & 1 & 986,68 & 0,0000 \\
\hline & & 2 & 1085,38 & 0,0000 \\
\hline & & 3 & 281,17 & 0,0000 \\
\hline & & 4 & 1753,07 & 0,0000 \\
\hline & \multirow{4}{*}{ ARCH-LM } & 1 & 25,13 & 0,0676 \\
\hline & & 2 & 51,95 & 0,0000 \\
\hline & & 3 & 8,33 & 0,9384 \\
\hline & & 4 & 32,73 & 0,0080 \\
\hline \multirow{8}{*}{$\Delta P I B_{t}^{B R} \Delta P I B_{t}^{P A} \Delta P_{t}^{B R} r_{t}$} & \multirow{4}{*}{ Jarque-Bera } & 1 & 921,45 & 0,0000 \\
\hline & & 2 & 2,58 & 0,2747 \\
\hline & & 3 & 175,55 & 0,0000 \\
\hline & & 4 & 0,28 & 0,8697 \\
\hline & \multirow{4}{*}{ ARCH-LM } & 1 & 13,81 & 0,6127 \\
\hline & & 2 & 7,13 & 0,9707 \\
\hline & & 3 & 22,70 & 0,1220 \\
\hline & & 4 & 17,99 & 0,3244 \\
\hline \multirow{8}{*}{$\Delta P I B_{t}^{B R} \Delta P I B_{t}^{P E} \Delta P_{t}^{B R} r_{t}$} & \multirow{4}{*}{ Jarque-Bera } & 1 & 1549,43 & 0,0000 \\
\hline & & 2 & 18,57 & 0,0001 \\
\hline & & 3 & 274,98 & 0,0000 \\
\hline & & 4 & 1350,28 & 0,0000 \\
\hline & \multirow{4}{*}{ ARCH-LM } & 1 & 12,86 & 0,6830 \\
\hline & & 2 & 32,25 & 0,0093 \\
\hline & & 3 & 7,93 & 0,9510 \\
\hline & & 4 & 30,69 & 0,0148 \\
\hline \multirow{8}{*}{$\Delta P I B_{t}^{B R} \Delta P I B_{t}^{P R} \Delta P_{t}^{B R} r_{t}$} & \multirow{4}{*}{ Jarque-Bera } & 1 & 1196,08 & 0,0000 \\
\hline & & 2 & 3,27 & 0,1952 \\
\hline & & 3 & 223,13 & 0,0000 \\
\hline & & 4 & 1401,46 & 0,0000 \\
\hline & \multirow{4}{*}{ ARCH-LM } & 1 & 17,98 & 0,3252 \\
\hline & & 2 & 23,63 & 0,0978 \\
\hline & & 3 & 7,76 & 0,9556 \\
\hline & & 4 & 28,84 & 0,0250 \\
\hline \multirow{8}{*}{$\Delta P I B_{t}^{B R} \Delta P I B_{t}^{R J} \Delta P_{t}^{B R} r_{t}$} & \multirow{4}{*}{ Jarque-Bera } & 1 & 1290,07 & 0,0000 \\
\hline & & 2 & 7039,02 & 0,0000 \\
\hline & & 3 & 216,29 & 0,0000 \\
\hline & & 4 & 1583,00 & 0,0000 \\
\hline & \multirow{4}{*}{ ARCH-LM } & 1 & 14,47 & 0,5640 \\
\hline & & 2 & 32,02 & 0,0099 \\
\hline & & 3 & 9,55 & 0,8891 \\
\hline & & 4 & 33,90 & 0,0056 \\
\hline
\end{tabular}

Fonte: Elaboração própria. *Testes de normalidade: Hipótese nula: resíduos são normais. ${ }^{* *}$ O teste $A R C H-L M$ usa a hipótese nula de ausência de heterocedasticidade auto-regressiva condicional. Regra geral de decisão: $p$-value $>0,05$, aceita a hipótese nula. 
Tabela A-4: Testes de Normalidade: Jarque-Bera e ARCH-LM

\begin{tabular}{|c|c|c|c|c|}
\hline Modelo & Teste & Componente & Estatística & P-value $\left(\chi^{2}\right)$ \\
\hline \multirow{8}{*}{$\Delta P I B_{t}^{B R} \Delta P I B_{t}^{R S} \Delta P_{t}^{B R} r_{t}$} & \multirow{4}{*}{ Jarque-Bera } & 1 & 1174,73 & 0,0000 \\
\hline & & 2 & 77,58 & 0,0000 \\
\hline & & 3 & 218,21 & 0,0000 \\
\hline & & 4 & 1778,17 & 0,0000 \\
\hline & \multirow{4}{*}{ ARCH-LM } & 1 & 17,50 & 0,3538 \\
\hline & & 2 & 28,09 & 0,0308 \\
\hline & & 3 & 7,52 & 0,9619 \\
\hline & & 4 & 28,10 & 0,0307 \\
\hline \multirow{8}{*}{$\Delta P I B_{t}^{B R} \Delta P I B_{t}^{S C} \Delta P_{t}^{B R} r_{t}$} & \multirow{4}{*}{ Jarque-Bera } & 1 & 1164,80 & 0,0000 \\
\hline & & 2 & 8,72 & 0,0127 \\
\hline & & 3 & 256,73 & 0,0000 \\
\hline & & 4 & 1539,95 & 0,0000 \\
\hline & \multirow{4}{*}{ ARCH-LM } & 1 & 16,83 & 0,3968 \\
\hline & & 2 & 10,03 & 0,8653 \\
\hline & & 3 & 7,00 & 0,9732 \\
\hline & & 4 & 31,49 & 0,0116 \\
\hline \multirow{8}{*}{$\Delta P I B_{t}^{B R} \Delta P I B_{t}^{S P} \Delta P_{t}^{B R} r_{t}$} & \multirow{4}{*}{ Jarque-Bera } & 1 & 885,61 & 0,0000 \\
\hline & & 2 & 212,37 & 0,0000 \\
\hline & & 3 & 141,93 & 0,0000 \\
\hline & & 4 & 1731,88 & 0,0000 \\
\hline & \multirow{4}{*}{ ARCH-LM } & 1 & 19,26 & 0,2553 \\
\hline & & 2 & 2,52 & 0,9999 \\
\hline & & 3 & 11,52 & 0,7761 \\
\hline & & 4 & 33,07 & 0,0072 \\
\hline
\end{tabular}

Fonte: Elaboração própria. *Testes de normalidade: Hipótese nula: resíduos são normais. ${ }^{* *}$ O teste $A R C H-L M$ usa a hipótese nula de ausência de heterocedasticidade auto-regressiva condicional. Regra geral de decisão: p-value $>0,05$, aceita a hipótese nula. 
Tabela A-5: Descrição das Variáveis Utilizadas para Estimar o Modelo 2

\begin{tabular}{|c|c|c|}
\hline Variáveis & Descrição & Fonte \\
\hline $\begin{array}{l}\% \text { Estabelecimentos } \\
\text { Industriais }\end{array}$ & $\begin{array}{l}\text { Estabelecimentos Industriais dividido por Total } \\
\text { Estabelecimentos - TABELA } 988\end{array}$ & $\begin{array}{l}\text { Fonte: IBGE - Cadas- } \\
\text { tro Central de Empre- } \\
\text { sas - } 2008\end{array}$ \\
\hline $\begin{array}{l}\text { \% Estabelecimentos } \\
\text { Industriais Transfor- } \\
\text { mação }\end{array}$ & $\begin{array}{l}\text { Estabelecimentos Indústria Transformação divi- } \\
\text { dido por Total Estabelecimentos - TABELA } 988\end{array}$ & $\begin{array}{l}\text { Fonte: IBGE - Cadas- } \\
\text { tro Central de Empre- } \\
\text { sas - } 2008\end{array}$ \\
\hline $\begin{array}{l}\% \text { Indústrias extrati- } \\
\text { vas }\end{array}$ & $\begin{array}{l}\text { Estabelecimentos Indústria Extrativista dividido } \\
\text { por Total Estabelecimentos - TABELA } 988\end{array}$ & $\begin{array}{l}\text { Fonte: IBGE - Cadas- } \\
\text { tro Central de Empre- } \\
\text { sas - } 2008\end{array}$ \\
\hline Grau de Abertura & Exportação - Importação dividido pelo PIB & Fonte: SECEX -2008 \\
\hline $\begin{array}{l}\text { \% Estabelecimentos } \\
\text { Industriais com } 500 \\
\text { ou mais empregados }\end{array}$ & $\begin{array}{l}\text { Percentual Estabelecimentos da industria da } \\
\text { transformação com } 500 \text { ou mais empregados - TA- } \\
\text { BELA } 988\end{array}$ & $\begin{array}{l}\text { Fonte: IBGE - Cadas- } \\
\text { tro Central de Empre- } \\
\text { sas - } 2008\end{array}$ \\
\hline $\begin{array}{l}\text { Média de Depósitos } \\
\text { por Agências ponde- } \\
\text { rado pelo PIB }\end{array}$ & $\begin{array}{l}\text { Média de Depósitos por Agências ponderado pelo } \\
\text { PIB }\end{array}$ & Fonte: Banco Central \\
\hline $\begin{array}{l}\text { \% Unidades Locais } \\
\text { com } 250 \text { ou mais pes- } \\
\text { soal ocupado }\end{array}$ & $\begin{array}{l}\text { Percentual das Unidades Locais com } 250 \text { ou mais } \\
\text { pessoal ocupado - TABELA } 988\end{array}$ & $\begin{array}{l}\text { Fonte: IBGE - Cadas- } \\
\text { tro Central de Empre- } \\
\text { sas - } 2008\end{array}$ \\
\hline $\begin{array}{l}\% \text { Bancos com } 0 \text { a } 4 \\
\text { empregados }\end{array}$ & $\begin{array}{l}\text { Participação dos Estabelecimentos financeiros } \\
\text { com } 0 \text { a } 4 \text { empregados no Total de Estabelecimen- } \\
\text { tos financeiros - TABELA } 988\end{array}$ & $\begin{array}{l}\text { Fonte: IBGE - Cadas- } \\
\text { tro Central de Empre- } \\
\text { sas - } 2008\end{array}$ \\
\hline $\begin{array}{l}\text { \% Emprego Público / } \\
\text { Emprego total }\end{array}$ & $\begin{array}{l}\text { Participação do Emprego Público no Total de Em- } \\
\text { prego }\end{array}$ & $\begin{array}{l}\text { Fonte: RAIS-MTE - } \\
2008\end{array}$ \\
\hline Densidade & População dividida pela área geográfica & $\begin{array}{l}\text { Censo Demográfico - } \\
2007\end{array}$ \\
\hline Índice de Diversidade & $\begin{array}{l}\text { Índice calculado por divisão de atividades ( } 2 \text { dí- } \\
\text { gitos) da indústria da transformação segundo a } \\
\text { CNAE } 2.0 \text { com base na variável emprego. }\end{array}$ & RAIS-Mte - 2006 \\
\hline Capital Humano & Capital Humano & IPEADATA - 2000 \\
\hline
\end{tabular}

Fonte: Elaboração própria. 


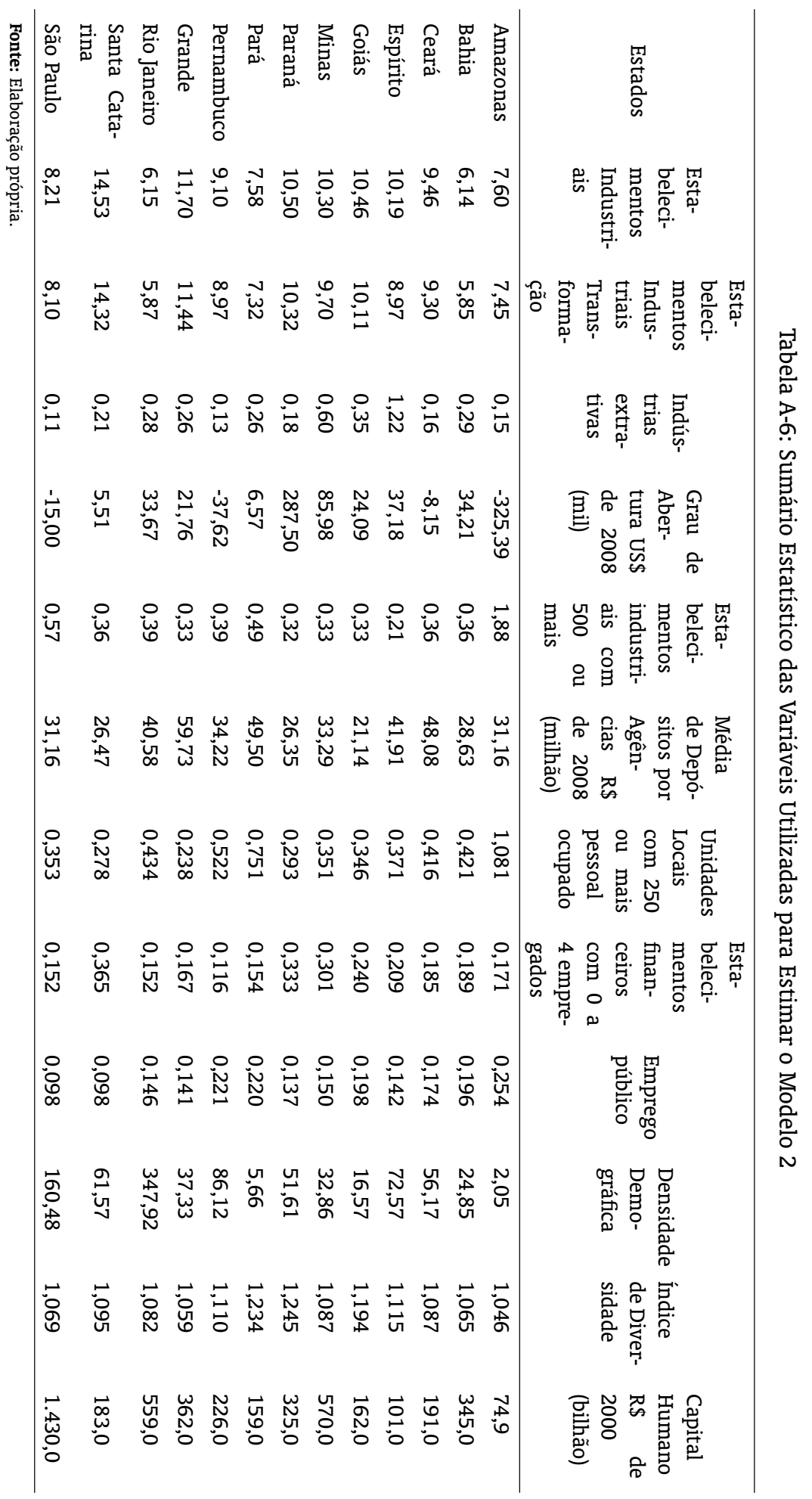




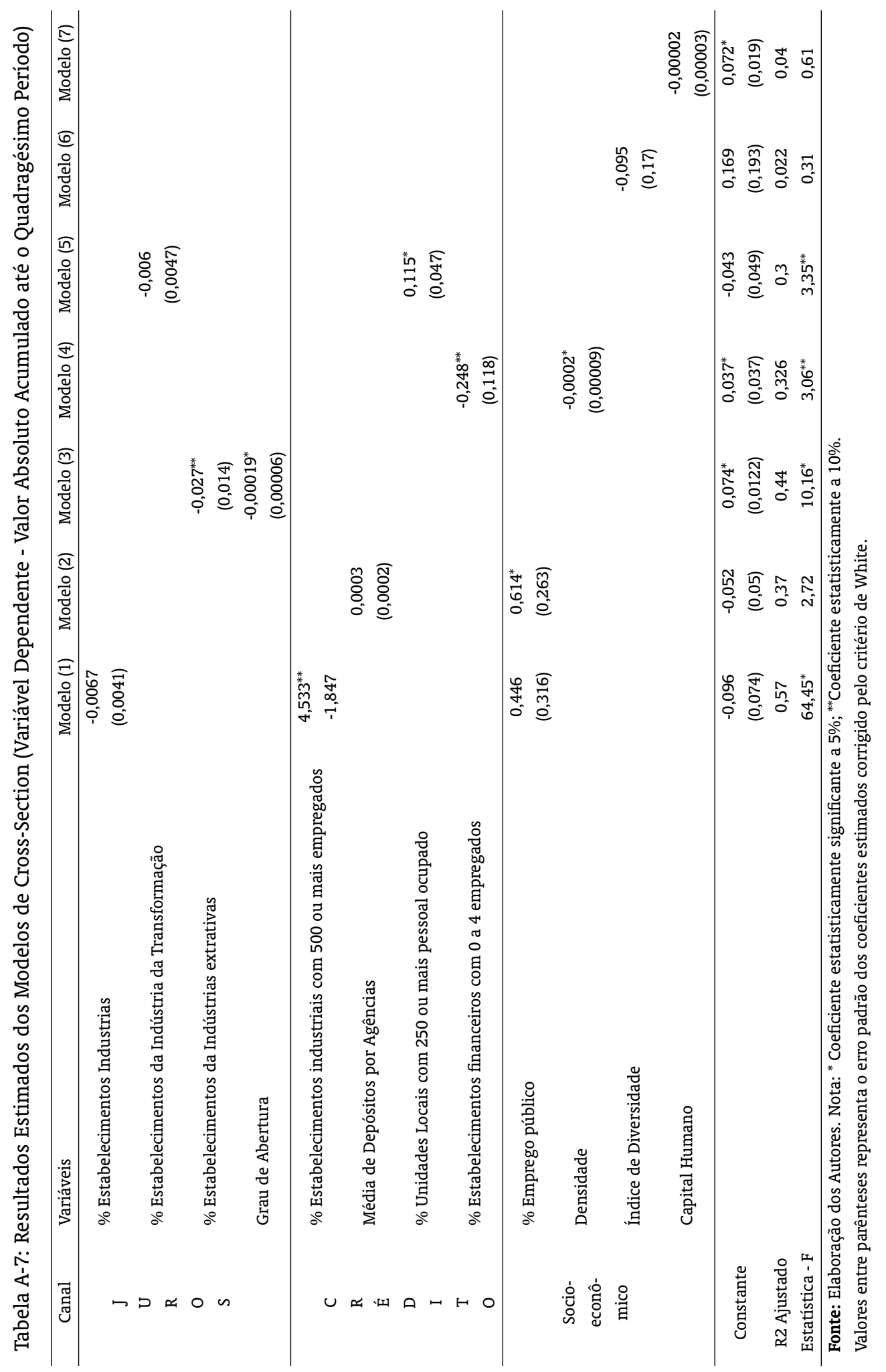

RBE Rio de Janeiro $\quad$ v. 65 n. 4 / p. 413-441 Out-Dez 2011 